OPEN ACCESS

Edited by:

Patrick Rollin,

Université d'Orléans, France

Reviewed by:

Clemens Zwergel,

Sapienza University of Rome, Italy

Rajeev K. Singla,

Sichuan University, China

*Correspondence:

Irina loannou

irina.ioannou@agroparistech.fr

Florent Allais

florent.allais@agroparistech.fr

tORCID:

V. P. Thinh Nguyen orcid.org/0000-0002-2499-2900

Irina loannou

orcid.org/0000-0002-1914-2717

Florent Allais

orcid.org/0000-0003-4132-6210

Specialty section:

This article was submitted to

Medicinal and Pharmaceutical

Chemistry,

a section of the journal

Frontiers in Chemistry

Received: 05 February 2021

Accepted: 28 April 2021

Published: 14 May 2021

Citation:

Nguyen VPT, Stewart JD, loannou I and Allais F (2021) Sinapic Acid and Sinapate Esters in Brassica: Innate

Accumulation, Biosynthesis,

Accessibility via Chemical Synthesis or

Recovery From Biomass, and

Biological Activities.

Front. Chem. 9:664602.

doi: 10.3389/fchem.2021.664602

\section{Sinapic Acid and Sinapate Esters in Brassica: Innate Accumulation, Biosynthesis, Accessibility via Chemical Synthesis or Recovery From Biomass, and Biological Activities}

\author{
V. P. Thinh Nguyen ${ }^{1,2 t}$, Jon D. Stewart ${ }^{2}$, Irina loannou ${ }^{1 \star t}$ and Florent Allais ${ }^{1,2 \star t}$
}

${ }^{1}$ URD Agro-Biotechnologies Industrielles (ABI), CEBB, AgroParisTech, Pomacle, France, ${ }^{2}$ Department of Chemistry, University of Florida, Gainesville, FL, United States

Sinapic acid (SinA) and corresponding esters are secondary metabolites abundantly found in plants of Brassica family. Belonging to the family of $p$-hydroxycinnamic acids, SinA and its esters analogues are present in different plant parts and involved in multiple biological processes in planta. Moreover, these metabolites are also found in relatively large quantities in agro-industrial wastes. Nowadays, these metabolites are increasingly drawing attention due to their bioactivities which include antioxidant, anti-microbial, anti-cancer and UV filtering activities. As a result, these metabolites find applications in pharmaceutical, cosmetic and food industries. In this context, this article reviews innate occurrence, biosynthesis, accessibility via chemical synthesis or direct extraction from agro-industrial wastes. Biological activities of SinA and its main corresponding esters will also be discussed.

Keywords: Brassica, $p$-hydroxycinnamic acids, sinapic acid, sinapine, sinapoyl glucose, sinapoyl malate

\section{INTRODUCTION}

p-Hydroxycinnamic acids represent one of the most widely distributed chemicals in the plant kingdom, along with other phenylpropanoids such as flavonoids, stilbenes, and lignans. $p$-Hydroxycinnamic acids occur in fruits, vegetables, cereals, and beverages and are involved in plant tissue development and response to external stress (Nicholson and Hammerschmidt, 1992; Beckman, 2000).

Primary roles of $p$-hydroxycinnamic acids in different parts of plants include coloration of flowers that attract pollinating animals, protection from injurious UV radiation, natural aromas and tastes that defend against predators, resistances to pathogens, and enhancing the host plants by affecting the growth of other, neighboring plants (Beckman, 2000).

Sinapoyl esters (SinEs) are the most important $p$-hydroxycinnamoyl esters present in plants of the Brassicaceae species (Nićiforović and Abramovič, 2014; Chen, 2016). SinEs possess a $p$-hydroxyphenol moiety with two methoxy substituents at the meta-positions. Along with its free acid form sinapic acid (SinA) (1), many SinEs have been found in plants, such as sinapoyl choline [also known as sinapine (2)], sinapoyl malate (3), sinapoyl glucose (4), and many more. The structure of SinA and its major corresponding esters present in this review are illustrated and listed in Figure $\mathbf{1 .}$

SinEs have various biological properties such as antimicrobial (Maddox et al., 2010; Engels et al., 2012), anti-inflammatory (Yun et al., 2008; Oueslati et al., 2012), anticancer (Oueslati et al., 2012; 
<smiles>COc1cc(/C=C/C(=O)O)cc(OC)c1O</smiles>

Sinapic Acid

(1)<smiles>COc1cc(/C=C/C(=O)O[C@@H](CC(=O)O)C(=O)O)cc(OC)c1O</smiles>

Sinapoyl malate

(3)<smiles>[X][N+](C)(C)CCOC(=O)C=Cc1cc(OC)c(O)c(OC)c1</smiles>

Sinapoyl choline

(2)<smiles>COc1cc(/C=C/C(=O)O[C@@H]2O[C@H](CO)[C@@H](O)[C@H](O)[C@H]2O)cc(OC)c1O</smiles>

Sinapoyl glucose

(4)

FIGURE 1 | Structures of SinA and its main corresponding esters present in this review.

Raj Preeth et al., 2019; Boeing et al., 2020), and anti-anxiety activities (Yoon et al., 2007). Moreover, it is suggested that SinEs could be used as food and cosmetic additives, as well as bioactive compounds in the pharmaceutical industry (Nićiforović and Abramovič, 2014). SinA, the carboxylic acid form of SinE, could be employed as a building block for the design of renewable monomers and polymers (Jaufurally et al., 2016; Janvier et al., 2017; Hollande et al., 2019).

Here, we review the innate accumulation of p-hydroxycinnamic acid and its derivatives in Brassica plants, mainly focusing on SinA and SinE. Moreover, we will discuss their biosynthesis, accessibility via chemical synthesis or direct extraction, and biological activities.

\section{INNATE ACCUMULATION OF SINAPIC ACID AND ITS DERIVATIVES IN BRASSICA}

Phenylpropanoids are omnipresent in the plant kingdom and have been identified in a wide variety of edible plants including fruits, vegetables, cereals, and spices. The concentration of $\operatorname{Sin} A$ and its derivatives varies from one species to another. For instance, strawberries, Fragaria ananassa L., was reported to possess the highest concentration of $\operatorname{SinE}$ (up to $450.30 \mu \mathrm{g} / \mathrm{g}$ of biomass), while the lowest concentration was determined in rye Secale cereale $L$. (a few $\mu \mathrm{g} / \mathrm{g}$ of biomass) (Nićiforović and Abramovič, 2014). The review by Niciforovic and Abramovic provides a detailed report on the natural occurrence of these phenolic compounds (Nićiforović and Abramovič, 2014). Within the Brassicaceae vegetables, SinA and its derivatives are ubiquitously present in both free and esterified forms. Many SinEs have been identified in different species from Brassica family (Lin and Harnly, 2010; Cartea et al., 2011). Generally, the concentration of naturally occurring SinA appears to be lower than its choline ester, sinapine. The concentrations of SinEs, mainly sinapine, range from 8 to
$10.4 \mathrm{mg} / \mathrm{g}$ of biomass, whereas SinA ranges from 0.49 to $2.49 \mathrm{mg} / \mathrm{g}$ of biomass (Thiel et al., 2015; Odinot et al., 2017; Reungoat et al., 2020).

The accumulation of phenolic compounds has been probed within different parts of Brassica plants. Many SinEs have been identified in edible parts such as leaves, stems, flower buds, and roots (Fernandes et al., 2007). Malate derivatives were determined to be the main $p$-hydroxycinnamic esters presented in the leaves of pak choi Brassica campestris L subsp. chinensis and Chinese mustard Brassica juncea Coss (Harbaum et al., 2008). SinA and its esters have also been found in large amounts within rapeseed seeds and in their defatted residues. In their study of rapeseed meal, Laguna et al. reported that the SinA concentration in nonindustrial and industrial meals, after alkaline hydrolysis, was up to 14.0 and $10.5 \mathrm{mg} / \mathrm{g}$ of dry matter, respectively (Laguna et al., 2019). Another study on aqueous ethanol extracts from mustard bran (B. juncea) reported that the sinapine concentration was up to $8.7 \mathrm{mg} / \mathrm{g}$ of dry matter (Reungoat et al., 2020).

The accumulation of SinA and its derivatives, along with other phenylpropanoids, is believed to favor the adaptation process in plants under environmental stresses. By soaking B. juncea seeds prior to germination in 24-epibrassinolide, Sharma et al. observed enhanced accumulation of phenolic compounds in the presence of imidacloprid (Sharma et al., 2016). The levels of SinA and its derivatives in seedlings that grew from soaked seeds were increased by over $100 \%$ compared to seedlings derived from untreated seeds. The accumulation of SinA and its derivatives also occurred under biotic stress including insect attack and pathogen infection. Gunnaiah et al. observed that the up-regulation of phenylpropanoid biosynthesis occurred in wheat infested with Fusarium graminearum, a fungal plant pathogen (Gunnaiah et al., 2012). An increased cell wall thickness prompted an excessive accumulation of $\operatorname{Sin} \mathrm{A}$ and its derivatives in infested plants, which is thought to be a physiological response to biotic stress. It was furthermore suggested that Brassica plants 

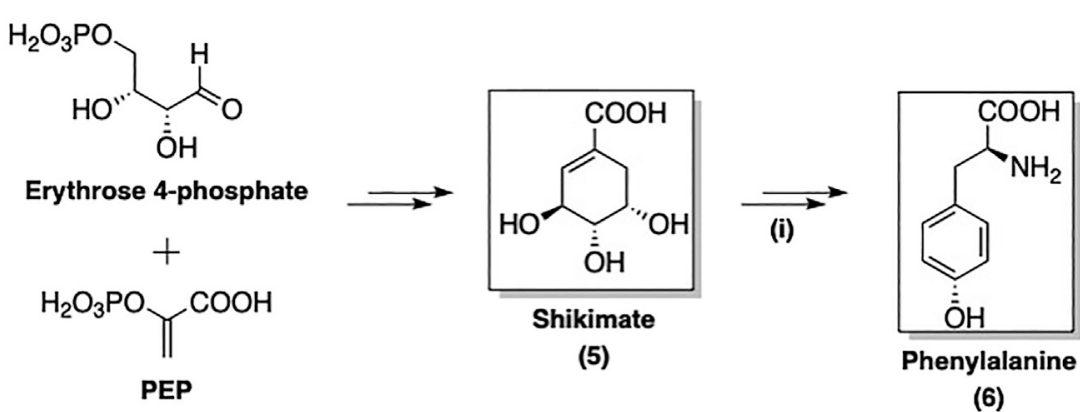

Phenylalanine

(6)

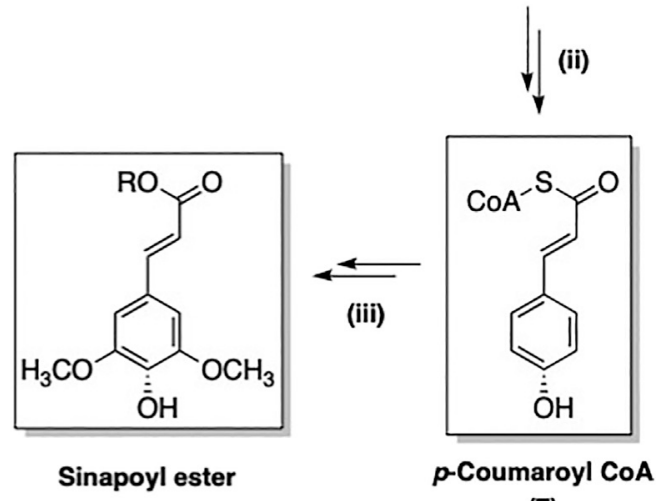

(7)

FIGURE 2 | Three main stages of SinE biosynthesis: (i): Formation of Phe; (ii): Formation 4-coumaroyl CoA intermediate; (iii) Formation of sinapoyl esters.

accumulate phenolics and other metabolites to enhance survival rates against environmental stresses, which is in agreement with Beckman et al.'s suggestion (Beckman, 2000).

The involvement of these secondary metabolites in response to environmental stresses, however, exacts a cost to the plants with regard to the energy devoted to accumulating phenolic compounds, which leads to lower growth rates. In the study conducted by Moreno et al., chinese cabbage (Brassica rapa $L$. subsp. Pekinenesis) grown under sub-optimal conditions accumulated higher phenolic concentrations than those grown under optimal conditions (Moreno et al., 2003). The weights of plants grown under sub-optimal conditions were, as a result, lower than those grown under optimal conditions.

The accumulation of $\operatorname{Sin} A$ and its derivatives varies with the growth environment since these modulate the physiological state of the plants. We therefore suggest that adverse environmental factors should be included in future studies in order to anticipate potential over-accumulation of these secondary metabolites. The concentration of SinA and its derivatives in plant can also be used as an indicator to monitor plant growth and the effects of growth conditions on plant development.

\section{BIOSYNTHESIS OF SINAPIC ACID AND DERIVATIVES}

Plant growth depends on environmental conditions and accumulating phenolics enables plants to survive under sub-optimal growth conditions (Blokhina et al., 2003; Toscano et al., 2019). SinA and its derivatives, along with other secondary metabolites, are biosynthesized by plants via a set of chemical reactions (Vogt, 2010). Studying these pathways within plants will therefore allow us to understand how environmental stresses affect phenolic accumulation generally, and more specifically, SinA and SinE in Brassica plants. In recent years, the biosynthesis of these secondary metabolites has been extensively studied thanks to the advanced development of model plants including Arabidopsis thaliana, a member of the Brassica family (Vogt, 2010; Fraser and Chapple, 2011).

The biosynthesis of SinA derivatives involves the phenylpropanoid pathway via the formation of shikimate intermediate (5). This route is composed of three sequential stages: (i) formation of phenylalanine (6) via the shikimate pathway; (ii) non-oxidative deamination of $\mathbf{6}$ followed by oxygenation to yield activated p-coumaroyl CoA (7); (iii) further transformations of 7 to afford a broad range of SinEs (Vogt, 2010). As an example, the biosynthesis of SinE from erythrose 4-phosphate and phosphoenolpyruvate (PEP) is shown in Figure 2.

\section{Formation of Phenylalanine Following Shikimate Pathway (i)}

As depicted in Figure 3, the formation of phenylalanine (6) starts with the 3-deoxy-D-heptulosonate 7-phosphate (DAHP) synthase-catalyzed condensation of PEP and erythrose 4phosphate to afford DAHP (Schmid and Amrhein, 1995). The 
<smiles>O=CC(O)C(O)COP(=O)(O)O</smiles>

Erythrose 4-phosphate<smiles>C=C([OH+][OH2+])C(=O)O</smiles>

PEP

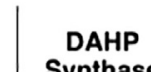

Synthase<smiles>O=C(O)C1(O)C[C@@H](O)[C@H](O)[C@@H](COP(=O)(O)O)O1</smiles>

DAHP

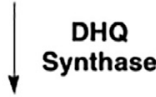

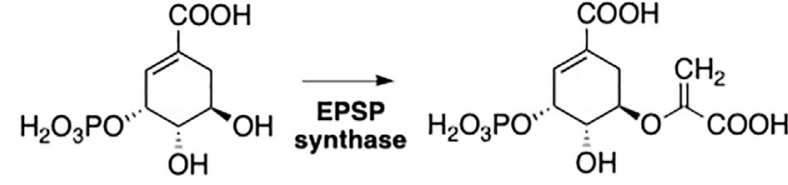

Shikimate 3-phosphate

Shikimate kinase<smiles>O=C(O)C1=C[C@H](O)[C@H](O)[C@H](O)C1</smiles>

(5) Shikimate: NADP oxidoreduction<smiles>O=C(O)C1=CC(=O)C(O)[C@H](O)C1</smiles>

5-Enolpyruvylshikimate

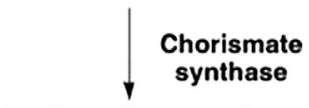

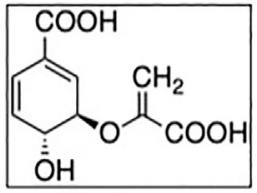

Chorismate

(8)

$$
\begin{gathered}
\text { Chorismate } \\
\text { mutase }
\end{gathered}
$$

HOOC

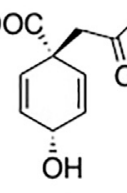

Prephenate

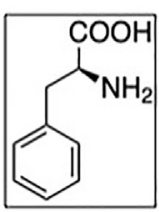

(6)
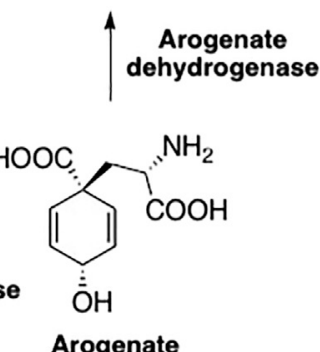

FIGURE 3 | Formation of phenylalanine following the shikimate pathway. Squared boxes indicate relevant intermediates.

latter is then transformed by 3-dehydroquinate synthase into 3dehydroquinate (DHQ) that is subsequently dehydrogenated and reduced by 3 -dehydroquinate dehydratase and the shikimate: nicotinamide adenine dinucleotide phosphate (NADP) oxidoreductase, respectively, to afford shikimate (5).

The multi-step conversion of $\mathbf{5}$ to phenylalanine requires its conversion to chorismate (8). Shikimate is phosphorylated by shikimate kinase to yield shikimate 3-phosphate. 5Enolpyruvylshikimate 3-phosphate (EPSP) synthase then installs a phosphoenolpyruvate group at the 5-position. Finally, chorismate synthase eliminates the phosphate group to afford 8.

Chorismate (8) is converted to prephenate via a chorismate mutase-catalyzed Claisen rearrangement of the enolpyruvyl side chain. Prephenate aminotransferase installs the amino group to yield arogenate, then this is simultaneously decarboxylated and dehydrated by arogenate dehydratase to yield $\mathbf{6}$.

The formation of aromatic amino acids from PEP and erythrose 4-phosphate has been well studied and many of these enzymes have been isolated and characterized (Herrmann and Weaver, 1999; Maeda and Dudareva, 2012). Detailed discussions of regulation and mechanisms for each of the enzymes involved in the shikimate pathway can be found in a number of previously published reviews (Schmid and Amrhein, 1995; Herrmann and Weaver, 1999; Maeda and Dudareva, 2012).

\section{Formation of 4-Coumaroyl CoA (ii)}

The conversion of phenylalanine (6) to 4-coumaroyl CoA (7) requires consecutive modifications by phenylalanine ammonia lyase $(\mathrm{PAL})$, cinnamate 4-hydroxylase $(\mathrm{C} 4 \mathrm{H})$, and 4-coumaroyl CoA-Ligase (4CL) (Vogt, 2010). The conversion of 4-coumaroyl CoA to its CoA-linked ester is illustrated in Figure 4.

The first step of this pathway involves the non-oxidative deamination of phenylalanine (6) catalyzed by PAL (Koukol and Conn, 1961). The proposed mechanism of PAL is similar to that of histidine ammonia lyase (MacDonald and D'Cunha, 2007). Although no exogenous cofactor is required, an electrophile is still needed for the deamination; hence, the enzyme contains a 3,5dihydro-5-methyldiene-4H-imidazol-4-one (9) moiety, formed by the cyclization and elimination of water from the inner tripeptide Ala-Ser-Gly (Jun et al., 2018). The mechanism of this conversion is shown in Figure 5.

$\mathrm{C} 4 \mathrm{H}$ belongs to the CYP73A family of P450 enzymes and catalyzes the hydroxylation of cinnamic acid (10) at the 4position, yielding 4-coumaric acid (11). This transformation requires NADPH-cytochrome $\mathrm{P} 450$ reductase, which acts as an electron donor (Werck-Reichhart and Feyereisen, 2000). The crystal structure of $\mathrm{C} 4 \mathrm{H}$ from Sorghum bicolor (PDB accession number 6VBY) was recently solved and provides critical structural insights into the substrate specificity of this enzyme (Zhang et al., 2020). The mechanism of the 


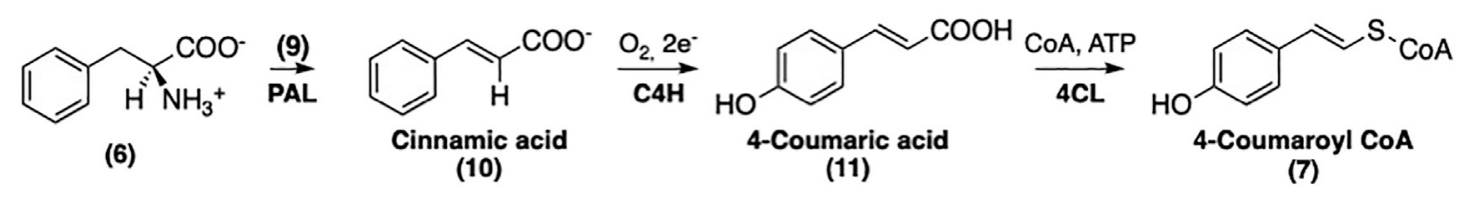

FIGURE 4 | The formation of 4-coumaroyl CoA.

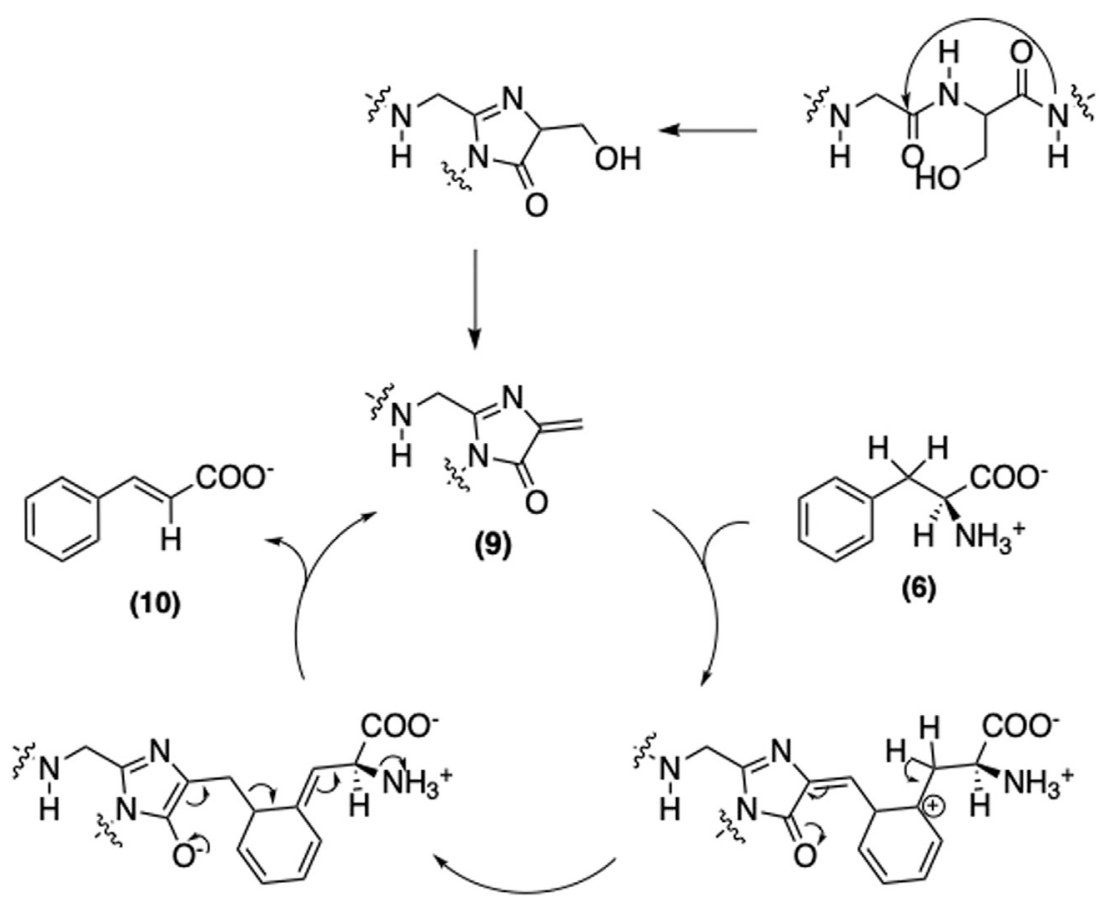

FIGURE 5 | Mechanism of the deamination of phenylalanine catalyzed by PAL.

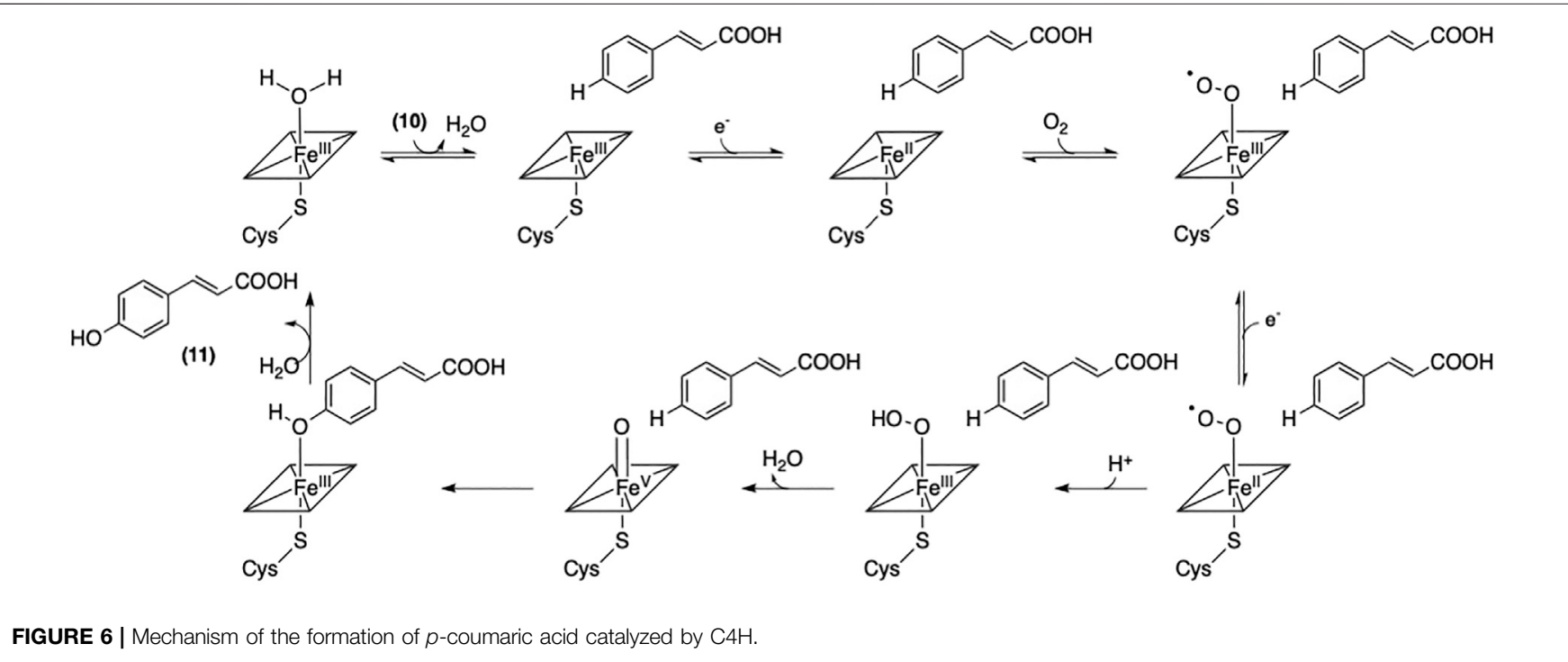


<smiles>O=C(C=Cc1ccc(O)cc1)S(=O)(=O)[O-]</smiles>

(7)<smiles></smiles>

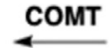
СОMT Sinapaldehyde $\downarrow$ REF<smiles>COc1cc(/C=C/C(=O)[O-])cc(OC)c1O</smiles>

Sinapate<smiles>O=C(O)C=Cc1ccc(O)c(O)c1</smiles>

Caffeoyl-CoA<smiles>COc1cc(/C=C/C(=O)[Se]O[Na])ccc1O</smiles>

Feruloyl-CoA

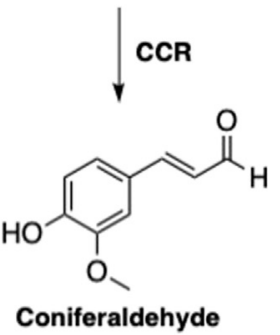

5-Hydroxyconiferaldehyde

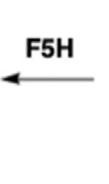

Coniferaldehyde

FIGURE 7 | Biosynthesis of sinapoyl esters. HCT: p-Hydroxycinnamoyl-CoA: quinate shikimate $p$-hydroxycinnamoyltransferase; COMT: Caffeic acid O-methyltransferase; CCR: Cinnamoyl-CoA reductase; F5H: Ferulate 5-hydroxylase; REF: Reduced Epidermal Fluorescence Aldehyde Dehydrogenase.

$\mathrm{C} 4 \mathrm{H}$-catalyzed transformation of $\mathbf{1 0}$ into 4-coumaric acid (11) is described in Figure 6.

The final step of this biosynthetic pathway involves the 4CLmediated conversion of (11) into the corresponding Coenzyme-A thioester (7). A reaction mechanism has been proposed by Knobloch and Hahlbrock (Knobloch and Hahlbrock, 1975). As depicted in Figure 4, the activation of $\mathbf{1 1}$ requires ATP and a CoA unit. The substrate specificity of 4CL has been well studied by Lindermayr et al. (Lindermayr et al., 2003); and. these authors have reported that recombinant $4 \mathrm{CL}$ can utilize several different $p$-hydroxycinnamic acids besides 11 including caffeic acid, ferulic acid, and $\operatorname{Sin} A$ to afford the corresponding CoA-linked thioesters. The recently published crystal structure of $4 \mathrm{CL}$ provided further insight into this enzyme with regard to its substrate specificity (Li and Nair, 2015). It is noteworthy that $4 \mathrm{CL}$ isoforms also contribute to the biosynthesis of lignin and other secondary metabolites in addition to its involvement in the biosynthesis of SinEs (Goujon et al., 2003; Soubeyrand et al., 2019). The mechanism of the conversion of $\mathbf{1 0}$ into $\mathbf{1 1}$ is described in Figure 6.

\section{Formation of Sinapic Acids and Derivatives (iii)}

An enzyme-catalyzed conversions of 4-coumaroyl CoA (7) to other phenolic-CoA esters following pathway of phenylpropanoid biosynthesis was suggested (Figure 7) (Boerjan et al., 2003). The first step of this biosynthetic pathway involves adding a hydroxyl group at the 3-position, which converts 7 to caffeoyl-CoA (Figure 8). Interestingly, this modification is catalyzed by $p$-hydroxycinnamoyl-CoA: quinate shikimate $p$-hydroxycinnamoyltransferase (HCT), which also catalyzes a condensation of $\mathbf{7}$ with $\mathbf{5}$ to form the corresponding $p$-coumaroyl-shikimate ester (Matsuno et al., 2009). A hydroxyl group is then added by CYP98A3 to afford the caffeoyl-shikimate ester. The transformation of caffeoylshikimate ester to caffeoyl-CoA is also catalyzed by HCT.

Caffeoyl CoA is next converted into feruloyl-CoA via methylation of the 3-hydroxyl by caffeic acid $\mathrm{O}$-methyltransferase (CMOT). It is noted that this enzyme also contributes to the defense systems in plants in addition to its involvement in phenylpropanoid biosynthesis (Wang et al., 2018). The resulting feruloyl-CoA is furthermore transformed by cinnamoyl-CoA reductase (CCR) to afford coniferaldehyde. Ferulate 5-hydroxylase (F5H) then adds a hydroxyl group onto the coniferaldehyde at the 5-position to provide 5-hydroxyconiferaldehyde. The 5-hydroxyl is then methylated by CMOT to yield sinapaldehyde. Finally, sinapate is formed from sinapaldehyde in the presence of reduced epidermal fluorescence 1 aldehyde dehydrogenase (Nair et al., 2004). 


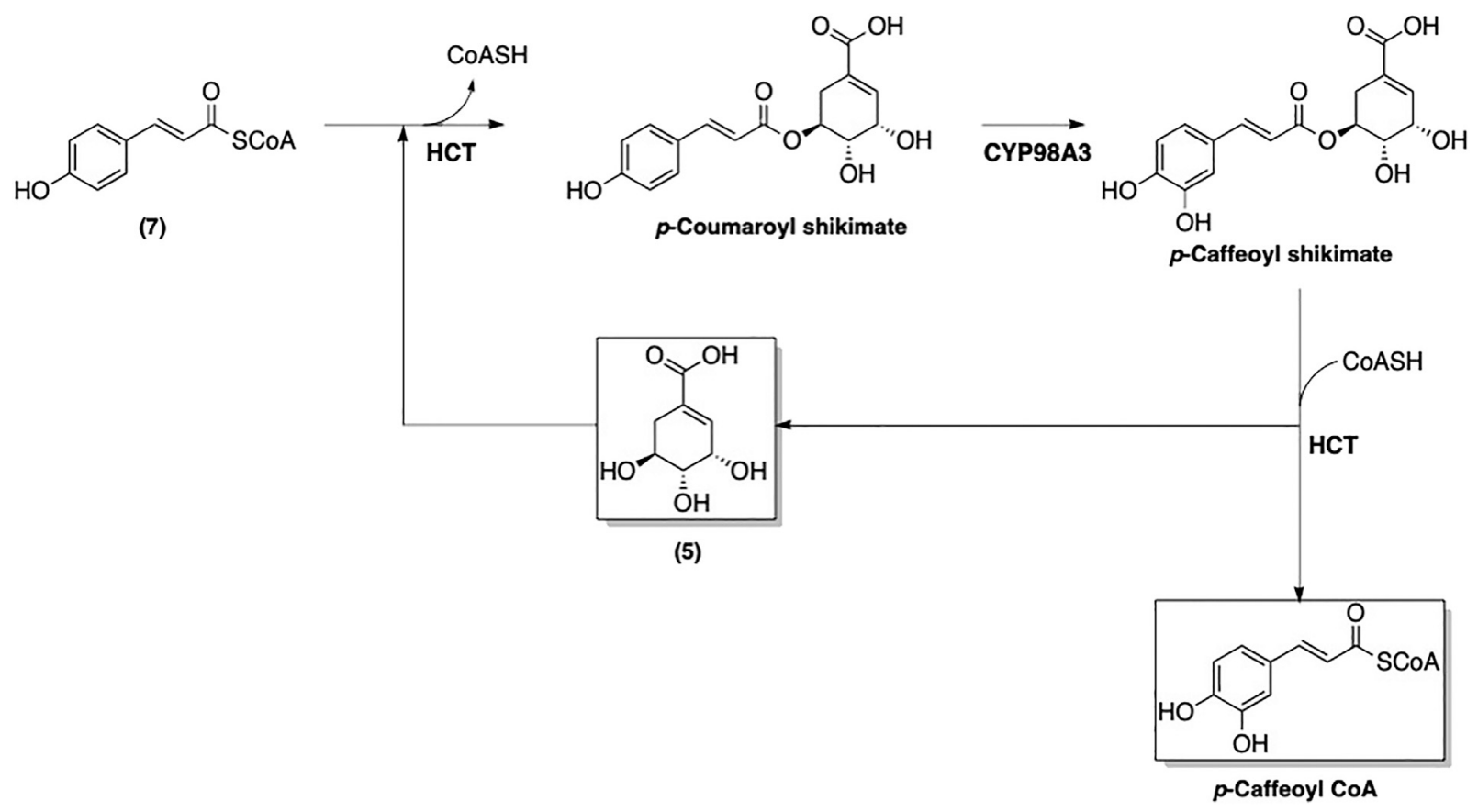

FIGURE 8 | Transformation of 4-coumaroyl CoA (7) into caffeoyl CoA.

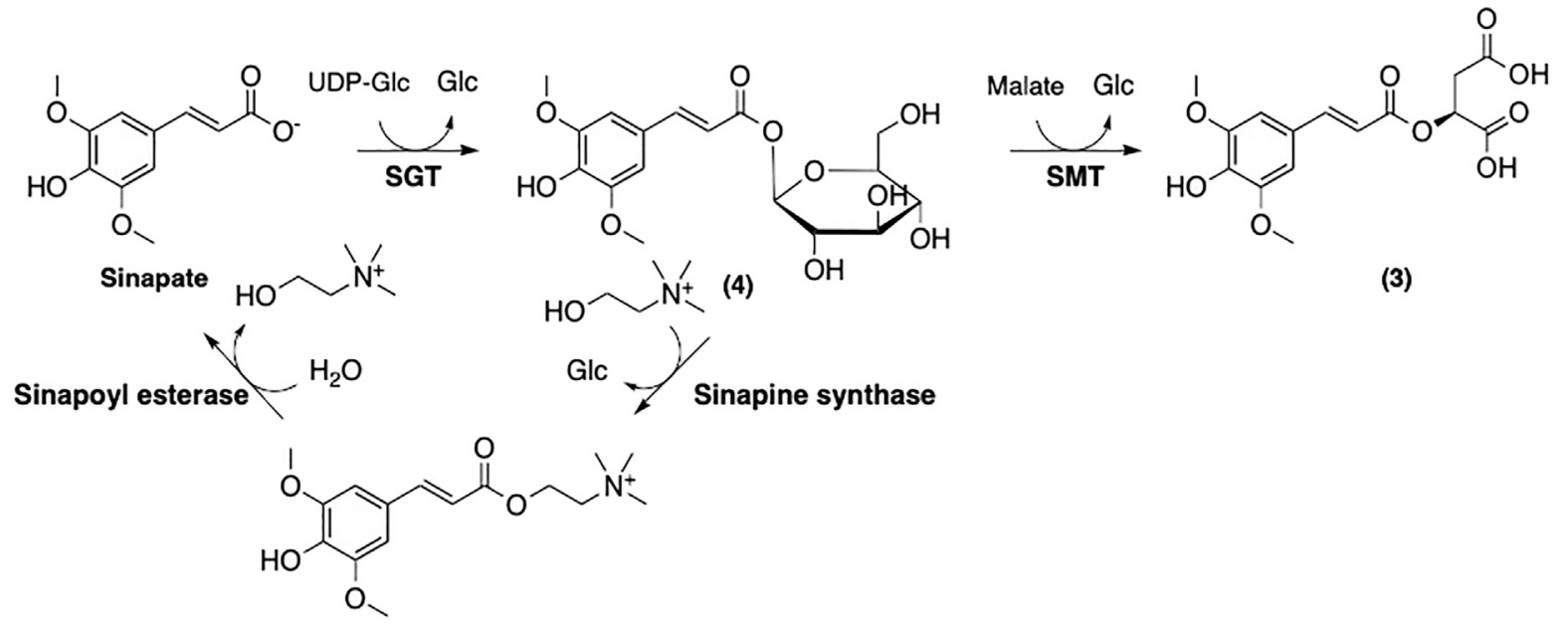

(2)

FIGURE 9 | Biosynthetic modification of sinapate to afford three main SinE in plants.

Further modifications of sinapate yield three main sinapoyl esters including sinapine (2), sinapoyl malate (3), and sinapoyl glucose (4) (Figure 9). It has been suggested that sinapoylglucose: malate sinapoyltransferase (SMT) is also responsible for the conversion of sinapate to 4 (Lorenzen et al., 1996). 1-OSinapoylglucose:choline sinapoyltransferase (also known as sinapine synthase) converts $\mathbf{4}$ to $\mathbf{2}$ (Vogt et al., 1993). Sinapoycholine esterase can also convert $\mathbf{2}$ back to $\mathbf{1}$ in order to provide the required amount of choline during the seedling stage (Clauß et al., 2011). On the other hand, replacing the glucose moiety of $\mathbf{4}$ by malate is catalyzed by sinapoylglucose: malate sinapoyltransferase (SMT), producing sinapoyl malate (3) (Lorenzen et al., 1996). By using these three sinapoyl esters as the main building blocks, plants produce a broad range of SinEs that are involved in many different biological processes (Nićiforović and Abramovič, 2014). 
<smiles>COc1cc(C=O)cc(OC)c1O</smiles>

Syringaldehyde (12)
Piperidine
Malonic acid

(13)<smiles>COc1cc(/C=C/C(=O)O)cc(OC)c1O</smiles>

(1)

FIGURE 10 | Synthesis of SinA via a sinapoyl malate-piperidine intermediate following the Knoevenagel-Doebner condensation approach.<smiles>COc1cc(/C=C/C(=O)O)cc(OC)c1O</smiles>

(1)<smiles>CCC[N+](C)(Br)CCBr</smiles>

(2)

FIGURE 11 | Synthesis of sinapine described by Clausen et al.

\section{CHEMICAL SYNTHETIC PATHWAY OF SINAPIC ACIDS AND DERIVATIVES}

\section{Sinapic Acid}

SinA can be readily synthesized chemically via a KnoevenagelDoebner condensation of syringaldehyde (12) and malonic acid (13) in piperidine (Figure 10) (Horbury et al., 2018; Flourat et al., 2020). Several greener approaches involving microwave activation (Mouterde and Allais, 2018) or L-proline as a catalyst in ethanol (Peyrot et al., 2019) have been developed in order to reduce the use of hazardous base and to enhance the overall yield and greenness of the synthetic process. Nevertheless, these improvements also have their own limitations. For example, substituting L-Pro for piperidine in ethanol requires an extra purification step by chromatography (Peyrot et al., 2019) whereas using piperidine as the catalyst requires only a simple acidic washing to afford pure SinA (Horbury et al., 2018). Taken together, the current protocols are straightforward and provide access to $\operatorname{Sin} \mathrm{A}$; however further improvements should be made in order to enhance the greenness of the process.

\section{Sinapate Esters}

\section{Sinapoyl Choline or Sinapine}

Sinapine is omnipresent in Brassica plants. The first synthetic approach to 2 was reported by Clausen et al. (Figure 11) (Clausen et al., 1982; Clausen et al., 1983). Using SinA isolated from Sinapis Alba L., and $\mathrm{AgNO}_{3}$, the corresponding SinA-Ag complex was reacted with bromocholine bromide to afford the pure product after chromatographic purification. Although pure sinapine was obtained, there were several drawbacks to this approach including low overall yield, toxic reagents and waste-generating purification steps.
Mouterde et al. have recently reported a more straightforward multigram-scale synthetic process for (2) (Figure 12) (Mouterde et al., 2020). Their approach relies on the well-established Knoevenagel-Doebner condensation of syringaldehyde and choline malonate. This two-step strategy gives access to desired $\operatorname{Sin} E$ in a decent overall yield, while avoiding the use of toxic reagents. This enhances both the cost-efficiency and the environmental friendliness of the process. Moreover, this method was reported to be applicable to other naturally occurring p-hydroxycinnamic acids such as coumaric, caffeic, and feruloyl acids. We believe that this approach is, to date, the most cost- and time-efficient protocol as well as the most attractive in the context of green chemistry.

\section{Sinapoyl Glucose}

Sinapoyl glucose is the precursor of sinapoyl malate (3) in SinE biosynthesis (Figure 9). The enzymatic conversion of p-hydroxycinnamic acid into the corresponding glucose derivative using recombinant Gomphrena globosa sinapate glucosyltransferase was studied by Matsuba et al. (Matsuba et al., 2008). This biochemical approach was applicable to most naturally occurring $p$-hydroxycinnamic acids such as ferulic acid, caffeic acid, 4-coumaric acid, and SinA. Unfortunately, the reported yield was low for sinapoyl and feruloyl glucose.

Zhu et al. therefore devised another synthetic strategy to overcome the limitations of the previous method (Zhu and Ralph, 2011). The authors carried out a stereoselective glycosylation between a protected glycosyl donor and 4-Ochloroacetylated $p$-hydroxycinnamic acids (either ferulic or sinapic acid) (Figure 13). The subsequent cleavage of the 


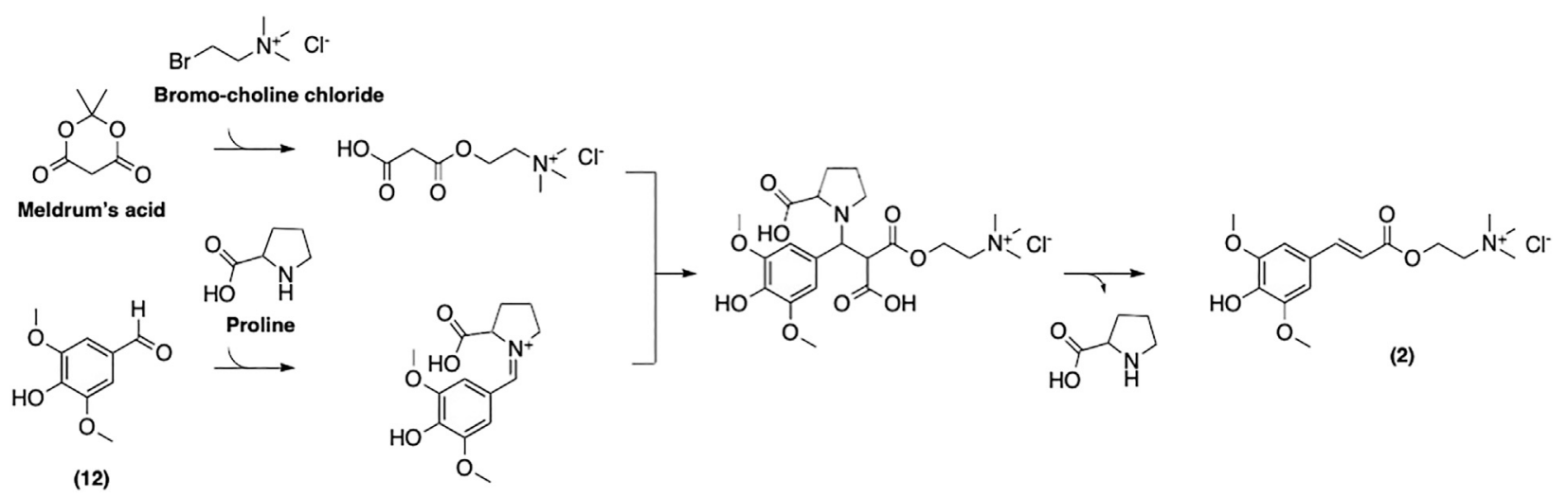

FIGURE 12 | Synthesis of sinapine described by Mouterde et al.
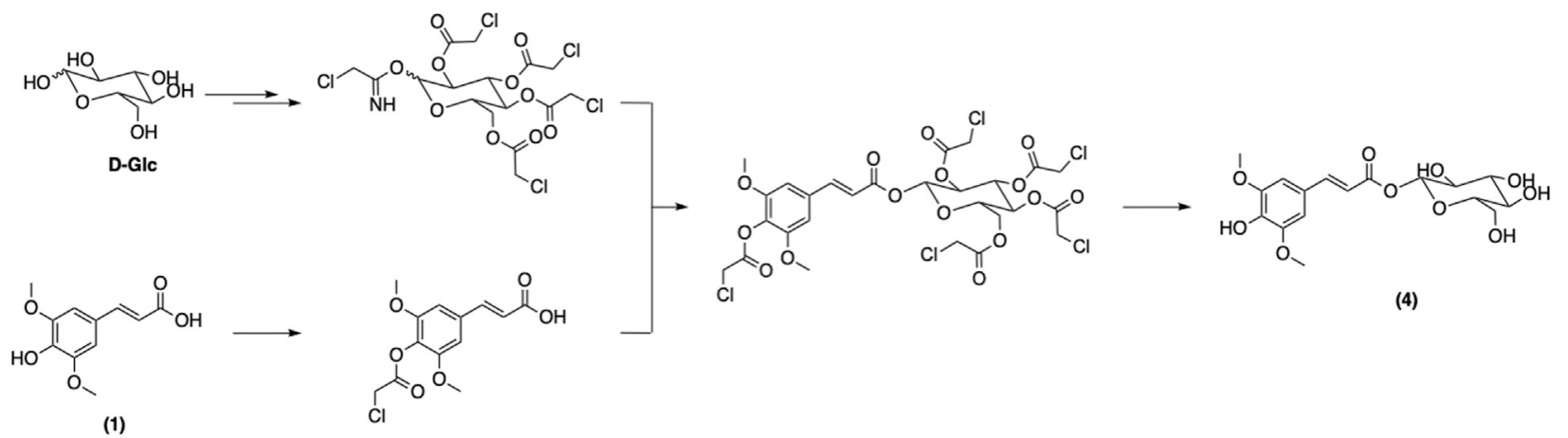

FIGURE 13 | Synthesis of sinapoyl glucose described by Zhu et al.
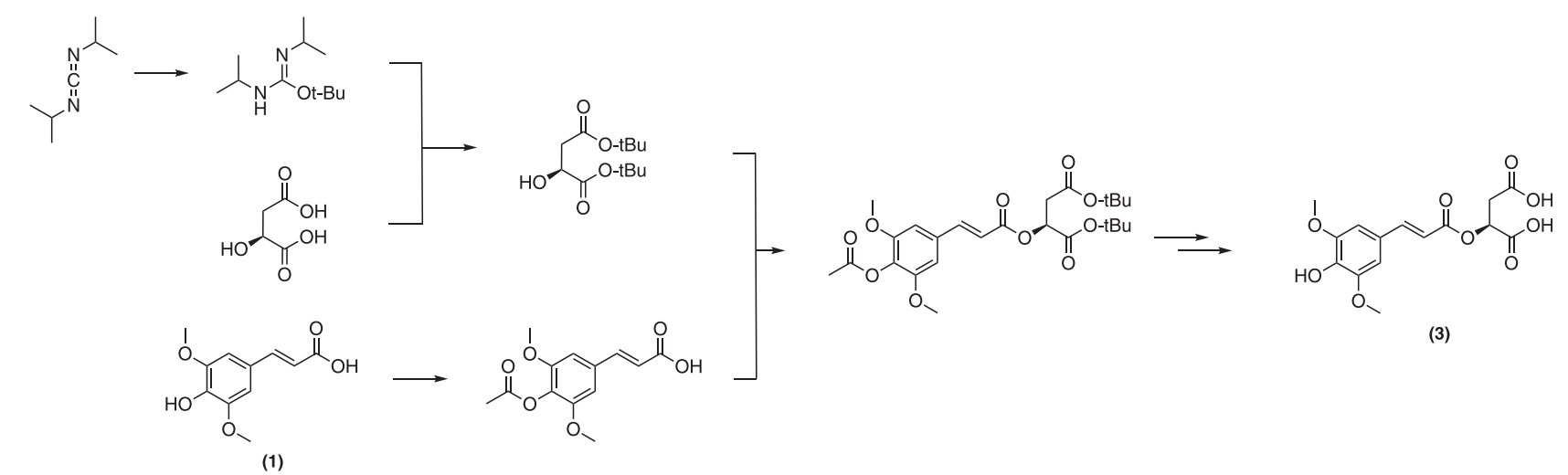

(3)

FIGURE 14 | Synthesis of sinapoyl malate described by Allais et al.

chloroacetyl groups was then performed under mild conditions to yield desired sinapoyl or feruloyl glucose derivatives. This method successfully furnished the sinapoyl glucose (4) in high yields. To the best of our knowledge, this synthetic strategy remains the most efficient way to obtain 4 . Nevertheless, one drawback is that this synthesis requires multiple protection/deprotection steps for both the sugar and the $p$-hydroxycinnamic moieties. 


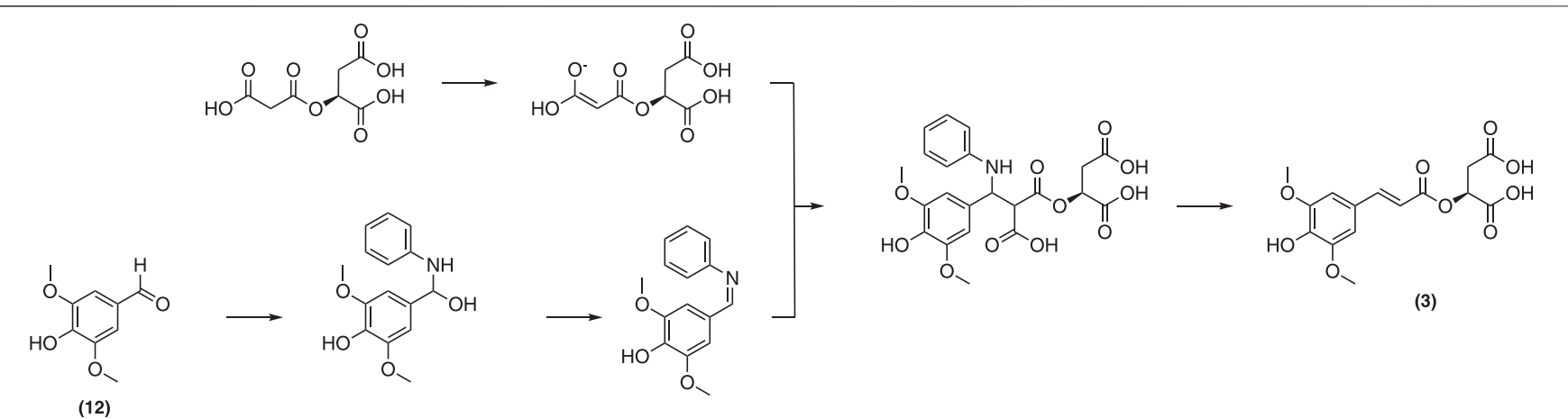

FIGURE 15 | Synthesis of sinapoyl malate described by Peyrot et al.<smiles>CCC(C)C(=O)O</smiles><smiles>CCCCNC(=O)/C=C/c1cc(OC)c(O)c(OC)c1</smiles><smiles>C=C(OC)C(C)OC(=O)/C=C/c1cc(OC)c(O)c(OC)c1</smiles><smiles>COc1ccccc1NC(=O)/C=C/c1cc(OC)c(O)c(OC)c1</smiles><smiles>COC(=O)CC(C)OC(=O)/C=C/c1cc(OC)c(O)c(OC)c1</smiles><smiles>COc1cc(/C=C/C(=O)Oc2c(OC)cccc2OC)cc(OC)c1O</smiles><smiles>COC(=O)CC(OC(=O)/C=C/c1cc(OC)c(O)c(OC)c1)C(=O)OC</smiles><smiles>COc1ccccc1OC(=O)/C=C/c1cc(OC)c(O)c(OC)c1</smiles><smiles>COc1cc(/C=C/C(=O)Oc2ccccc2C)cc(OC)c1O</smiles><smiles>COc1cc(/C=C/C(=O)Oc2cc(C)ccc2C(C)C)cc(OC)c1O</smiles><smiles>C=CCc1ccc(OC(=O)/C=C/c2cc(OC)c(O)c(OC)c2)c(OC)c1</smiles>

FIGURE 16 | Several structural examples of other sinapate esters.

\section{Sinapoyl Malate}

Biosynthesized from sinapoyl glucose (4) in planta, sinapoyl malate (3) is crucial for regulating lignin biosynthetic enzymes in plants (Goujon et al., 2003). A total synthesis of $\mathbf{3}$ was reported by Allais et al. (Allais et al., 2009). This strategy employed a convergent approach from sinapic acid (1) and the corresponding protected malate moiety to afford the desired malate ester (Figure 14).

Although pure final product was obtained with a decent yield, the extensive use of toxic solvents along with multiple protection/deprotection steps throughout the pathway will likely hinder of the application of this approach at multigramscales. With this in mind, Peyrot et al. have devised a more sustainable and straightforward, protecting group-free procedure based on the Knoevenagel-Doebner condensation of syringaldehyde (12) and malic monomalonate ester (Figure 15) (Peyrot et al., 2020b). Sinapoyl malate and analogues were thereby obtained in higher yields. In addition, the method is more environmentally friendly as it avoids toxic solvents and reagents as well as waste-generating protection/ deprotection steps. It is noteworthy to mention that sinapoyl malate (3) also helps plants to protect themselves from UV radiations. ${ }^{58}$

\section{Other Sinapoyl Esters}

Other synthetic SinEs are of great interest with regard to their photophysical and biological properties (Dean et al., 2014; Baker et al., 2018; Peyrot et al., 2020a). Most SinEs are obtained via Knoevenagel-Doebner condensations (Baker et al., 2018; Peyrot et al., 2020a). The is more advantageous than direct acid-catalyzed esterification of SinA, as it enables access to a larger range of SinEs while remaining simple and ecologically attractive (e.g., no protection/deprotection sequences). Some structural examples are shown in Figure 16. 


\section{RECOVERY OF AND PURIFICATION OF SINAPIC ACID AND DERIVATIVES FROM BRASSICA BIOMASS}

\section{Recovery of Sinapic Acids and Derivatives From Brassica Biomass}

The extraction of bioactive molecules from agro-industrial wastes has drawn increasing attention (Chuo et al., 2020; Flourat et al., 2020). The recovery of SinA and derivatives mainly relies on solid-liquid extraction where water/alcohol mixtures are often used as the extraction solvent (Prapakornwiriya and Diosady, 2014; Flourat et al., 2019; Laguna et al., 2019; Reungoat et al., 2020). Despite its popularity, only few optimization studies of the extraction process under these conditions have been reported. Indeed, most of the authors use high temperatures (close to the boiling point) to increase the yields of SinA and derivatives. However, Flourat et al. have optimized extraction conditions of sinapine from mustard bran using response surface methodology. An extraction temperature of $55^{\circ} \mathrm{C}$ with a concentration of $66 \%$ ethanol represents their optimal conditions (Flourat et al., 2019). Another optimization study revealed that $75^{\circ} \mathrm{C}$ and $55 \%$ ethanol lead to the highest yield from mustard bran (Reungoat et al., 2020). In summary, optimal conditions to recover SinA and SinEs from Brassica biomass must be considered as around $60 \%$ of alcohol and temperature ranged from $50^{\circ} \mathrm{C}$ to boiling point of using alcohol. Although water/methanol mixtures have been conventionally used to recover phenolics from processed biomass (Lin and Harnly, 2010; Prapakornwiriya and Diosady, 2014; Laguna et al., 2018), aqueous ethanol mixtures are more attractive thanks to the low toxicity of ethanol over the more hazardous methanol (Flourat et al., 2019; Reungoat et al., 2020).

Solid-liquid extraction using water/alcohol mixtures remain the conventional method to recover phenolic compounds from Brassica biomass thanks to its simplicity, time, and cost efficiency. This method, however, requires an additional purification step, as the use of mixture alcohol/water also extracts other non-phenolic compounds such as proteins, glucosinolates, carbohydrates and many other water-soluble chemicals. A more selective and straightforward recovery method of these secondary metabolites remains to be established.

An innovative recovery of $\operatorname{Sin} A$ and innate $\operatorname{Sin} E$ under corresponding alkyl ester form using different alcohols has been reported by Li and Guo (Li and Guo, 2017). Base-catalyzed alcohol extraction of rapeseed meal was conducted and followed by a purification by column chromatography with silica as stationary phase. The recovery of $\operatorname{Sin} E$ (methyl sinapate) was reported to be up to $7.2 \mathrm{mg} / \mathrm{g}$ of rapeseed meal. Several alkyl SinEs (including ethyl, propyl, butyl, hexyl, octyl, decyl and dodecyl sinapate) were obtained through this method; however, their purification proved difficult due to the similar polarity of the alcohol and the corresponding alkyl sinapate ester. It is worth mentioning that the subsequent valorization of carbohydrates and residual meal was included into the extraction process. In summary, this method allows to simultaneously isolate desired phenolic compounds under corresponding ester forms and other valuable components from rapeseed meal.

\section{Intensified Recovery of Sinapic Acid and Derivatives Using Physical Accelerators}

Intensified water/alcohol extraction techniques enhance the recovery of secondary metabolites from various Brassica biomass samples (Sparr Eskilsson and Björklund, 2000; Li et al., 2010; Dubie et al., 2013; Nandasiri et al., 2019). These advanced technologies are more time- and energy-efficient as compared to conventional extraction methods since they reduce the extraction temperature as well as the amount of extraction solvent required. This avoids the need for high alcohol concentrations and extended extraction durations. In this context, we provide in this section relevant examples of intensified SinA and derivative recovery from many that have reported in the literature.

Physical accelerators, such as ultrasound, have been employed in a number of studies (Dubie et al., 2013; Szydlowska-Czerniak and Tulodziecka, 2015; Yu et al., 2016). Dubie et al. reported that low-frequency, high-intensity ultrasound treatment $(20 \mathrm{kHz}$ and $0.5 \mathrm{~W} / \mathrm{ml}$ ) of $B$. juncea meal improves the aqueous ethanol extraction. Several parameters, i.e., extraction temperature, ethanol concentration, sonication duration, and solvent/ material ratio were subjected to a one-factor-at-a-time optimizations (Dubie et al., 2013). The results show that the extraction of SinA and derivatives under mild conditions $(70 \%$ $\mathrm{EtOH} /$ water for $30 \mathrm{~min}$ at $25^{\circ} \mathrm{C}$ ) yields comparable results to the conventional water/ethanol extraction that require an extended extraction time (70\% EtOH for 7 days at room temperature). These results furthermore confirm the interest of this intensification strategy.

Microwave-accelerated extraction also enhances the recovery of bioactive molecules by increasing the motion of free water molecules within the plant tissue which then releases the target metabolites (Sparr Eskilsson and Björklund, 2000). This extraction method is believed to be advantageous compared to the conventional method (Jokić et al., 2012; Yang et al., 2014; Zago et al., 2015; Yu et al., 2020). Jokic et al. studied the extraction of phenolics from broccoli using microwave treatment with aqueous methanol under optimal conditions (Jokić et al., 2012). Microwave irradiation reduces extraction time while enhancing the phenolic concentration in the extracts. Unfortunately, the relatively high cost of the microwave apparatus, along with undesired chemical reactions due to the application of high temperatures during the extraction hinders wider use of this method, despite its benefits (Khoddami et al., 2013).

Accelerated solvent extraction (ASE) is a technique carried out under high pressure and an inert atmosphere with a range of extraction temperatures from 35 to $200^{\circ} \mathrm{C}$. This intensification method has been applied to recover secondary metabolites from Brassica biomass (Mohn et al., 2007; Blažević et al., 2020; Nguyen et al., 2020), including SinA and its derivatives (Li and Guo, 2016; 
TABLE 1 | Biological activities and properties of SinA and SinEs reported in this review.

\begin{tabular}{|c|c|c|c|}
\hline Metabolite & $\begin{array}{l}\text { Biological } \\
\text { activities or } \\
\text { properties }\end{array}$ & Effects & Reference(s) \\
\hline \multirow[t]{13}{*}{$\operatorname{Sin} A(\mathbf{1})$} & Antioxidant & Good ABTS scavenging activity & Hussain et al. (2020) \\
\hline & Antioxidant & DPPH, ABTS, hydroxyl, and superoxide radical scavenging & Mathew et al. (2015) \\
\hline & UV-filter & Good absorption activity within UV-B region & Dean et al. (2014) \\
\hline & Antibacterial & $\begin{array}{l}\text { Inhibition on polygalacturonase- (54\%) and polygalacturonic acid lyase } \\
\text { activities (43\%) from Erwinia cartovora subsp. carotovra at } 400 \mu \mathrm{g} / \mathrm{ml}\end{array}$ & Lyon and McGill (1989) \\
\hline & Antibacterial & $\begin{array}{l}\text { High antibacterial activity of extract from rapeseed flour against different } \\
\text { strains of Escherichia coli }\end{array}$ & Nowak et al. (1992) \\
\hline & Anti-inflammatory & $\begin{array}{l}\text { Inhibition on different proinflammatory factors such as nitric oxide } \\
\text { synthase, cyclooxygase } 2 \text {, and proinflammatory cytokines via Factor- } \mathrm{BB} \\
\text { inactivation }\end{array}$ & Yun et al. (2008) \\
\hline & Anti-inflammatory & $\begin{array}{l}\text { Inhibition of monocyte adhesion to lipopolysaccharide-stimulated } \\
\text { endothelial cells }\end{array}$ & Calabriso et al. (2019) \\
\hline & Anticancer & $\begin{array}{l}\text { Cytotoxicity and anti-angiogenic activity of SinA-copper oxide } \\
\text { nanoparticles }\end{array}$ & Raj Preeth et al. (2019) \\
\hline & Anticancer & $\begin{array}{l}\text { Antitumor activity against colon (Caco-2) and cervical (HeLa, SiHa, and } \\
\text { C33a) human cancer cell lines of extract from Butia odorata noblick fruit }\end{array}$ & Boeing et al. (2020) \\
\hline & Antidiabetic & $\begin{array}{l}\text { Amelioration of hyperglycemia in streptozotocin-induced type 1-like } \\
\text { diabetic rats }\end{array}$ & Cherng et al. (2013) \\
\hline & Antidiabetic & $\begin{array}{l}\text { Prevention of the progression of diabetes mellitus in streptozotocin- } \\
\text { induced type } 2 \text { diabetic rats }\end{array}$ & Alaofi (2020) \\
\hline & Antihypertensive & $\begin{array}{l}\text { Effects on systolic blood pressure by attenuating fibrosis and oxidative } \\
\text { stress }\end{array}$ & Silambarasan et al. (2014) \\
\hline & Anti-anxiety & Anxiolytic property mediated via $\mathrm{GABA}_{\mathrm{A}}$ receptor in mice & Yoon et al. (2007) \\
\hline $\begin{array}{l}\text { Methyl/Ethyl sinapate (structure } \\
\text { shown in Figure 16) }\end{array}$ & UV-filter & UV-photostability and absorption of cis-and trans- isomers & $\begin{array}{l}\text { Baker et al. (2018), Horbury et al. } \\
\text { (2018) }\end{array}$ \\
\hline \multirow[t]{3}{*}{ Sinapine (2) } & Antioxidant & Good ABTS scavenging activity & Hussain et al. (2020) \\
\hline & Antioxidant & $\begin{array}{l}33.2 \text { and } 88.4 \% \text { at a molar ratio of } \operatorname{Sin} A \text { to } \mathrm{DPPH}^{\bullet} \text { of } 0.2 \text { and } 0.5 \text {, } \\
\text { respectively }\end{array}$ & $\begin{array}{l}\text { Kikuzaki et al. (2002), Nenadis and } \\
\text { Tsimidou (2002) }\end{array}$ \\
\hline & Antimicrobial & $\begin{array}{l}\text { Excellent antimicrobial activity against Escherichia coli } \mathrm{K} 12 \text { strain at } 10 \% \mathrm{w} \\
\text { concentration }\end{array}$ & Mouterde et al. (2020) \\
\hline \multirow[t]{4}{*}{ Sinapoyl malate $(\mathbf{3})$} & Antioxidant & DPPH scavenging $\left(\mathrm{EC}_{50}=10.6 \mathrm{nmol}\right)$ & Peyrot et al. (2020b) \\
\hline & UV-filter & $\begin{array}{l}\text { Good UV-absorption activity within UV-A }(315-400 \mathrm{~nm}) \text { and UV-B } \\
(280-315 \mathrm{~nm}) \text { regions }\end{array}$ & $\begin{array}{l}\text { Peyrot et al. (2020a), Peyrot et al. } \\
\text { (2020b) }\end{array}$ \\
\hline & UV-filter & Good absorption activity within UV-B region & Dean et al. (2014) \\
\hline & Antibacterial & Comparable antibacterial activity to phenoxyethanol & Peyrot et al. (2020b) \\
\hline Sinapoyl glucose (4) & Antioxidant & $35.8 \mathrm{mM}$ to scavenge $25 \times 10^{18} \mathrm{DPPH}$ radicals & Thiyam et al. (2006) \\
\hline
\end{tabular}

Nandasiri et al., 2019). Aqueous alcoholic extraction of phenolics at high temperature $\left(140-180^{\circ} \mathrm{C}\right)$ and high pressure resulted in better extraction yield than conventional method (Nandasiri et al., 2019). On the other hand, it was also reported that, under similar extraction conditions $\left(200^{\circ} \mathrm{C}, 20 \mathrm{~min}\right)$, SinA was degraded into canolol through decarboxylation ( $\mathrm{Li}$ and Guo, 2016). The relatively high cost of the extractor apparatus must also be considered a drawback for industrial scale applications.

Nowadays, supercritical carbon dioxide $\left(\mathrm{Sc}-\mathrm{CO}_{2}\right)$ as extraction solvent has become attractive as an environmentally friendly technique for the extraction of secondary metabolites. The advantages of using $\mathrm{Sc}-\mathrm{CO}_{2}$ for phenolic extraction from canola press cake over conventional methods was reported by $\mathrm{Li}$ et al. (Li et al., 2010). The results show that $\mathrm{Sc}-\mathrm{CO}_{2}$ extraction using ethanol as co-solvent enhances the extraction of phenolics, with ca. $10 \mathrm{mg}$ of phenolics extracted per gram of dry matter from selected biomass. In addition, this extraction method appears to avoid the conversion of sinapine into SinA during the extraction process. The major drawback is the need for very specific technical expertise as well as material costs.
Advanced extraction techniques exhibit many advantages in terms of time, solvent consumption, and energy efficiency. Ultrasound-accelerated extraction, microwave-assisted extraction, and $\mathrm{Sc}-\mathrm{CO}_{2}$ become more attractive in industrial scale whereas ASE is the most rapid and efficient method for recovering valuable chemicals from biomass in laboratory scale. Taken together, these intensification techniques allow a more profitable recovery of desired SinA and derivatives from selected Brassica biomass.

\section{Enzyme Assisted Recovery of Sinapic Acid and Derivatives}

Carbohydrase (Viscozyme L.) and pectinase (Rapidase) were used to assist the recovery of phenolics from cauliflower $(B$. oleracea $\mathrm{L}$ var. botrytis) outer leaves by disrupting linkages between phenolics and cell-wall polymers (Huynh et al., 2014). In this study, cauliflower leaves were pretreated with either carbohydrase or pectinase prior to aqueous alcohol extraction of phenolics. Multiple extraction parameters related to the enzyme 
pretreatment step including type of enzyme, concentration, incubation temperature, $\mathrm{pH}$, and time were studied. As a result, enhanced recovery yields were observed in enzyme pretreated samples.

Another study employing enzyme-assisted extraction of rapeseed meal was also disclosed by Laguna et al. (Laguna et al., 2019). Recombinant cinnamoyl or feruloyl esterase from Aspergillus niger was applied to the methanolic extract of rapeseed meal in order to hydrolyze ester linkages between $p$-hydroxycinnamic acids and carbohydrates. This enhanced the specific recovery of SinA.

Enzyme-assisted recovery becomes an attractive and environmentally friendly method to recover SinA and its derivatives from biomass. This approach is straightforward and accessible thanks to the convenient operating conditions. Nevertheless, the substrate specificity and the high cost of using enzymes limit the wide use of this methodology.

\section{Purification of Recovered Sinapic Acid and Derivatives}

The use of mixture alcohol/water enables the extraction of other non-phenolic compounds such as proteins, glucosinolates, carbohydrates and many other water-, alcohol- and water/ alcohol mixture soluble chemicals. Additional process is therefore necessary in order to recover $\operatorname{Sin} A$ and derivatives at the necessary levels of purity.

For this, three technologies are commonly used: membrane processes, liquid/liquid extraction and adsorption chromatography. The latter is often employed with many studies reported in literature (Prapakornwiriya and Diosady, 2014; Thiel et al., 2015; Odinot et al., 2017; Laguna et al., 2018). Crude biomass extracts were adjusted to acid $\mathrm{pH}$ values prior to loading onto preparative ion exchange columns. Bound SinA was then eluted with an aqueous alcohol solution. MorenoGonzalez et al. have improved the binding capacity by studying a large range of anionic resins (Moreno-González et al., 2020). The authors further showed that, compared to the batch adsorption method, the column adsorption approach afforded higher selectivity towards $\operatorname{Sin} A$, which led to a higher recovery rate. Although the adsorption/desorption approach allows an efficient recovery of $\operatorname{Sin} \mathrm{A}$ on preparative scales, sinapine was not recovered in its native ester form, as this method takes advantage of charge differences between sinapine and SinA.

Liquid-liquid extraction (LLE) is commonly used as a preparation step, at the analytical stage, to measure the phenolic content in plant extracts. First step consists of increasing the partition coefficient by acidifying the extracts to pH 2 (Berthod and Carda-Broch, 2004). Aprotic organic solvents such as diethyl ether (DE) and ethyl acetate (EA) were then used to recover desired phenolics (Dabrowski and Sosulski, 1984; Galanakis et al., 2013). Unfortunately, this technique is solvent-consuming, and, therefore, does not fit into a sustainable context.

Membrane processes are also employed to isolate desired phenolic compounds from Brassica biomass (Xu and Diosady, 2002; Sinichi et al., 2019). Biomass was extracted under usual alkaline conditions and the extracts were then filtered multiple times through selected membranes until reaching the optimized purity. Adjusting $\mathrm{pH}$ to acid between filtration steps was often required to separate desired $\operatorname{Sin} A$ from proteins and other undesired compounds ( $\mathrm{Xu}$ and Diosady, 2002; Sinichi et al., 2019). The efficiency of these process was reported between 70 and $90 \%$.

Although membrane processes are rapid and efficient purification techniques, however the purity is lower than that of adsorption chromatography. Hence, the adsorption chromatography, despite being cost- and time consuming, remains the conventional purification method for SinA and derivatives.

\section{Biological Activities}

Along with other ubiquitous $p$-hydroxycinnamic acids in the plant kingdom, SinA and its derivatives have been extensively studied regarding their biological activities (Neelam et al., 2020; Sova and Saso, 2020). Mainly recognized as potent antioxidant reagents, these metabolites are particularly of interest regarding their antibacterial and UV-filter properties along with many other health benefits (Taofiq et al., 2017; Sova and Saso, 2020). Here, biological activities and properties of $\operatorname{Sin} A$ and its main corresponding SinEs including sinapine, sinapoyl malate, and sinapoyl glucose, are discussed and summarized in Table $\mathbf{1 .}$

\section{Antioxidant Activity}

Free radical and other oxidizing reagents are generated during metabolic processes. These compounds lead to oxidative stress in the body and are often associated to numerous human diseases (Taofiq et al., 2017; Sova and Saso, 2020). Antioxidant reagents scavenge these free radical and oxidizing reagents, thus efficiently reducing their harmful effects (Cartea et al., 2011).

$p$-Hydroxycinnamic acids including SinA and corresponding SinEs are prominent as potent antioxidants. The radical scavenging activity of SinA for 2,2-diphenyl-1-picrylhydrazyl $\left(\mathrm{DPPH}^{\circ}\right)$ was determined to be 33.2 and $88.4 \%$ at a molar ratio of $\operatorname{Sin} \mathrm{A}$ to $\mathrm{DPPH}^{\bullet}$ of 0.2 and 0.5 , respectively (Kikuzaki et al., 2002; Nenadis and Tsimidou, 2002). Sinapine, on the other hand, exhibits even higher antioxidant activity than SinA (Thiyam et al., 2006). The antioxidant activities of sinapoyl malate and sinapoyl glucose were reported to be comparable to conventional antioxidants such as butylated hydroxyanisol (BHA), butylated hydroxytoluene (BHT), or trolox (Thiyam et al., 2006; Peyrot et al., 2020b). In addition, antioxidant activity of Canola meal extract was also studied by Hussain et al. (Hussain et al., 2020). Their results showed that SinA and sinapine exhibited good radical scavenging activity towards 2,2'-azinobis (3-ethylbenzothiazoline-6-sulfonic acid) (ABTS). We highly recommend reviews by Niciforovič and Abramovič (Nićiforović and Abramovič, 2014) and Chen (Chen, 2016) for further details concerning the free radical scavenging activity of SinA and other derivatives toward other free radical molecules such as superoxide anion radicals, hydroperoxyl radical, hypochlorite, and nitric oxide.

The antioxidant property of $p$-hydroxycinnamic acids mainly relies on the hydroxyl group at the para-position (Pei et al., 2016). 
Besides this characteristic functional group, addition of extra hydroxyl groups on to the phenyl core allows higher radical and oxidizing reagent scavenging activities. For instance, caffeic acid shows better antioxidant activity than that of SinA (Mathew et al., 2015). Furthermore, extra methoxyl group on the $p$-hydroxycinnamic acid core further improves the radical scavenging activities of these metabolites (Mouterde et al., 2020).

\section{UV-Filter Activities}

Sunscreen lotions are often advised to avoid permanent skin damages due to long-term light exposure. $p$-hydroxycinnamic acids such as ferulic and caffeic acid are supplemented in these cosmetical products to improve skin protection efficiency (Kumar and Pruthi, 2014; Taofiq et al., 2017; Coman and Vodnar, 2020).

As prominent $p$-hydroxycinnamic acid, SinA and its derivatives also exhibit high photo-stability and UV-absorption (Dean et al., 2014; Horbury et al., 2019; Peyrot et al., 2020a). The photophysical properties of numerous synthetic SinEs were recently studied by Peyrot et al. (Peyrot et al., 2020a; Peyrot et al., 2020b) who have reported comparable, or even better, photo-activities of these synthetic $p$-hydroxycinnamic acids than octinoxate (a conventional fossil-based UV-filter reagent) in term of UV absorption and photostability.

It is noteworthy that the structural conformation of these metabolite plays an important role in the UV activities. The activities of $\operatorname{Sin} \mathrm{A}$ and its derivatives are mainly attributed to the trans-isomers, whereas the cis-isomers have shown limited absorption thresholds (Baker et al., 2018; Horbury et al., 2018) and exhibit genotoxicity activity (Sharma et al., 2017). In order to address this symmetric drawback, addition of an acrylic functional group by the esterification of $\operatorname{SinE}$ allows to negating the aforementioned negative effects (Horbury et al., 2019).

\section{Antimicrobial Activity}

The antimicrobial activities of SinA and its derivatives have also been well studied. In an early study (Lyon and McGill, 1989), the antimicrobial activity of SinA against Erwinia carotovora subsp. carotovora which causes foodborne illness in root vegetables was reported. Inhibition of a broad range of Gram-negative and Gram-positive bacteria have also been demonstrated using a SinA fraction isolated from the ethanolic extract of rapeseed (Nowak et al., 1992). The antimicrobial activities of sinapine (Mouterde et al., 2020) and other SinEs (Peyrot et al., 2020b) against Escherichia coli have also been recently highlighted. These literature reports strongly suggest that SinA and its derivatives are potential biobased antimicrobial reagents.

\section{Other Health Benefits}

Many human health benefits of SinA and derivatives have been reported, and these include anti-inflammatory (Yun et al., 2008; Calabriso et al., 2019), anticancer (Raj Preeth et al., 2019; Boeing et al., 2020), anti-diabetic (Cherng et al., 2013; Alaofi, 2020), and antihypertensive properties (Silambarasan et al., 2014) as well as their protections of the nervous, respiratory, and digestive systems
(Sova and Saso, 2020). For further details on the health benefits of these metabolites, we highly recommend the reviews by Sova and Saso (Sova and Saso, 2020) and by Neelam et al. (Neelam et al., 2020).

\section{CONCLUSION}

The therapeutic and biological benefits of SinA and its derivatives have been extensively studied. Although the use of advanced extraction techniques to recover these metabolites remains limited, mainly due to their relatively high cost, the accessibility of these metabolites from biomass extraction has been improved. Meanwhile, chemical synthesis of natural and non-natural SinEs through sustainable approaches have been devised to provide a straightforward access to these molecules while taking into account the environmental impacts of the processes. Biochemical studies of SinA and its derivatives have been also been extended to provide crucial information concerning their innate accumulation and their important biological roles in plants.

As mentioned above, Sin A and its common derivatives including sinapine, sinapoyl malate, and sinapoyl glucose, exhibit many valuable properties for human health beyond their well-known antioxidant and antibacterial activities. Their photo-physical properties are also important for applications as biobased UV-filters. Further extended SinEs, with regards to their interesting biological activities, also represent attractive ingredients in the pharmaceutical, cosmetic and food industries.

We believe that SinA and derivates are prospective bio-based substitutes for conventional antioxidants with regards to their high antioxidant and antimicrobial activities, along with many other health benefits. These metabolites are furthermore potential sustainable and non-toxic alternatives to the conventional UVfilters that are currently flagged as human- and eco-toxic (Burnett and Wang, 2011; Krause et al., 2012). Despite several aforementioned limitations, $\operatorname{Sin} A$ and its derivatives represent potential multifunctional chemicals with a bright future that deserves to be further investigated and developed.

\section{AUTHOR CONTRIBUTIONS}

VN wrote the draft; JS, II and FA reviewed the draft and finalized the manuscript; JS and FA obtained fundings; II and FA supervised the work.

\section{FUNDING}

This research was funded by the National Institute of Food and Agriculture, United States Department of Agriculture, under award number 2016-11231. The authors also thank Grand Reims, Département de la Marne and Grand Est region, as well as the Fondation Paris-Reims, for funding. 


\section{REFERENCES}

Alaofi, A. L. (2020). Sinapic Acid Ameliorates the Progression of Streptozotocin (STZ)-Induced Diabetic Nephropathy in Rats via NRF2/HO-1 Mediated Pathways. Front. Pharmacol. 11, 1-11. doi:10.3389/fphar.2020.01119

Allais, F., Ducrot, P.-H., and Martinet, S. (2009). Straightforward Total Synthesis of 2-O-Feruloyl-L-Malate, 2-O-Sinapoyl-L-Malate and 2-O-5-HydroxyferuloylL-Malate. Synthesis (Stuttg) 2009, 3571-3578. doi:10.1055/s-0029-1216983

Baker, L. A., Staniforth, M., Flourat, A. L., Allais, F., and Stavros, V. G. (2018). GasSolution Phase Transient Absorption Study of the Plant Sunscreen Derivative Methyl Sinapate. ChemPhotoChem 2, 743-748. doi:10.1002/cptc.201800060

Beckman, C. H. (2000). Phenolic-storing Cells: Keys to Programmed Cell Death and Periderm Formation in Wilt Disease Resistance and in General Defence Responses in Plants?. Physiol. Mol. Plant Pathol. 57, 101-110. doi:10.1006/ pmpp.2000.0287

Berthod, A., and Carda-Broch, S. (2004). Determination of Liquid-Liquid Partition Coefficients by Separation Methods. J. Chromatogr. A 1037, 3-14. doi:10.1016/j. chroma.2004.01.001

Blažević, I., Montaut, S., Burčul, F., Olsen, C. E., Burow, M., Rollin, P., et al. (2020). Glucosinolate Structural Diversity, Identification, Chemical Synthesis and Metabolism in Plants. Phytochemistry 169, 112100. doi:10.1016/j.phytochem. 2019.112100

Blokhina, O., Virolainen, E., and Fagerstedt, K. V. (2003). Antioxidants, Oxidative Damage and Oxygen Deprivation Stress: A Review. Ann. Bot. 91, 179-194. doi:10.1093/aob/mcf118

Boeing, J. S., Barizão, É. O., Rotta, E. M., Volpato, H., Nakamura, C. V., Maldaner, L., et al. (2020). Phenolic Compounds from Butia Odorata (Barb. Rodr.) Noblick Fruit and its Antioxidant and Antitumor Activities. Food Anal. Methods 13, 61-68. doi:10.1007/s12161-019-01515-6

Boerjan, W., Ralph, J., and Baucher, M. (2003). Ligninbiosynthesis. Annu. Rev. Plant Biol. 54, 519-546. doi:10.1146/annurev.arplant.54.031902.134938

Burnett, M. E., and Wang, S. Q. (2011). Current Sunscreen Controversies: A Critical Review. Photodermatol. Photoimmunol. Photomed. 27, 58-67. doi:10. 1111/j.1600-0781.2011.00557.x

Calabriso, N., Massaro, M., Scoditti, E., Pasqualone, A., Laddomada, B., and Carluccio, M. A. (2019). Phenolic Extracts from Whole Wheat Biofortified Bread Dampen Overwhelming Inflammatory Response in Human Endothelial Cells and Monocytes: Major Role of VCAM-1 and CXCL-10. Eur. J. Nutr. 59, 2603-2615. doi:10.1007/s00394-019-02109-y

Cartea, M. E., Francisco, M., Soengas, P., and Velasco, P. (2011). Phenolic Compounds in Brassica Vegetables. Molecules 16, 251-280. doi:10.3390/ molecules16010251

Chen, C. (2016). Sinapic Acid and its Derivatives as Medicine in Oxidative StressInduced Diseases and Aging. Oxidative Med. Cell Longevity, 2016 2016, 1, 10. doi:10.1155/2016/3571614

Cherng, Y.-G., Tsai, C.-C., Chung, H.-H., Lai, Y.-W., Kuo, S.-C., and Cheng, J.-T. (2013). Antihyperglycemic Action of Sinapic Acid in Diabetic Rats. J. Agric. Food Chem. 61, 12053-12059. doi:10.1021/jf403092b

Chuo, S. C., Nasir, H. M., Mohd-Setapar, S. H., Mohamed, S. F., Ahmad, A., Wani, W. A., et al. (2020). A Glimpse into the Extraction Methods of Active Compounds from Plants. Crit. Rev. Anal. Chem. 0, 1-30. doi:10.1080/ 10408347.2020.1820851

Clausen, S., Olsen, O., and Serensen, H. (1982). 4-Hydroxybenzoylcholine: A Natural Product Present in Sinapis Alba. Phytochemistry 21, 917-922. doi:10. 1016/0031-9422(82)80093-9

Clausen, S., Olsen, O., and Sørensen, H. (1983). Separation of Aromatic Choline Esters by High-Performance Liquid Chromatography. J. Chromatogr. A 260, 193-199. doi:10.1016/0021-9673(83)80026-0

Clauß, K., von Roepenack-Lahaye, E., Böttcher, C., Roth, M. R., Welti, R., Erban, A., et al. (2011). Overexpression of Sinapine Esterase BnSCE3 in Oilseed Rape Seeds Triggers Global Changes in Seed Metabolism. Plant Physiol. 155, 1127-1145. doi:10.1104/pp.110.169821

Coman, V., and Vodnar, D. C. (2020). Hydroxycinnamic Acids and Human Health: Recent Advances. J. Sci. Food Agric. 100, 483-499. doi:10.1002/jsfa.10010

Dabrowski, K. J., and Sosulski, F. W. (1984). Quantitation of Free and Hydrolyzable Phenolic Acids in Seeds by Capillary Gas-Liquid Chromatography. J. Agric. Food Chem. 32, 123-127. doi:10.1021/jf00121a031
Dean, J. C., Kusaka, R., Walsh, P. S., Allais, F., and Zwier, T. S. (2014). Plant Sunscreens in the UV-B: Ultraviolet Spectroscopy of Jet-Cooled Sinapoyl Malate, Sinapic Acid, and Sinapate Ester Derivatives. J. Am. Chem. Soc. 136, 14780-14795. doi:10.1021/ja5059026

Dubie, J., Stancik, A., Morra, M., and Nindo, C. (2013). Antioxidant Extraction from Mustard (Brassica Juncea) Seed Meal Using High-Intensity Ultrasound. J. Food Sci. 78, E542-E548. doi:10.1111/1750-3841.12085

Engels, C., Schieber, A., and Gänzle, M. G. (2012). Sinapic Acid Derivatives in Defatted Oriental Mustard (Brassica Juncea L.) Seed Meal Extracts Using UHPLC-DAD-ESI-MS $\mathrm{N}$ and Identification of Compounds with Antibacterial Activity. Eur. Food Res. Technol. 234, 535-542. doi:10.1007/ s00217-012-1669-z

Fernandes, F., Valentão, P., Sousa, C., Pereira, J., Seabra, R., and Andrade, P. (2007). Chemical and Antioxidative Assessment of Dietary Turnip (Brassica Rapa Var. Rapa L.). Food Chem. 105, 1003-1010. doi:10.1016/j.foodchem.2007. 04.063

Flourat, A. L., Combes, J., Bailly-Maitre-Grand, C., Magnien, K., Haudrechy, A., Renault, J. H., et al. (2020). Accessing P -Hydroxycinnamic Acids: Chemical Synthesis, Biomass Recovery, or Engineered Microbial Production? ChemSusChem 14, 118-129. doi:10.1002/cssc.202002141

Flourat, A. L., Willig, G., Teixeira, A. R. S., and Allais, F. (2019). Eco-Friendly Extraction of Sinapine from Residues of Mustard Production. Front. Sustain. Food Syst. 3, 12. doi:10.3389/fsufs.2019.00012

Fraser, C. M., and Chapple, C. (2011). The Phenylpropanoid Pathway in Arabidopsis. The Arabidopsis Book 9, e0152. doi:10.1199/tab.0152

Galanakis, C. M., Goulas, V., Tsakona, S., Manganaris, G. A., and Gekas, V. (2013) A Knowledge Base for the Recovery of Natural Phenols with Different Solvents. Int. J. Food Properties 16, 382-396. doi:10.1080/10942912.2010.522750

Goujon, T., Sibout, R., Pollet, B., Maba, B., Nussaume, L., Bechtold, N., et al. (2003). A New Arabidopsis thaliana Mutant Deficient in the Expression of O-Methyltransferase Impacts Lignins and Sinapoyl Esters. Plant Mol. Biol. 51, 973-989. doi:10.1023/A:1023022825098

Gunnaiah, R., Kushalappa, A. C., Duggavathi, R., Fox, S., and Somers, D. J. (2012). Integrated Metabolo-Proteomic Approach to Decipher the Mechanisms by Which Wheat Qtl (Fhb1) Contributes to Resistance against Fusarium Graminearum. PLoS One 7, e40695. doi:10.1371/journal.pone.0040695

Harbaum, B., Hubbermann, E. M., Zhu, Z., and Schwarz, K. (2008). Free and Bound Phenolic Compounds in Leaves of Pak Choi (Brassica Campestris L. Ssp. Chinensis Var. Communis) and Chinese Leaf Mustard (Brassica Juncea Coss). Food Chem. 110, 838-846. doi:10.1016/j.foodchem.2008.02.069

Herrmann, K. M., and Weaver, L. M. (1999). The Shikimate Pathway. Annu. Rev. Plant Physiol. Plant Mol. Biol. 50, 473-503. doi:10.1146/annurev.arplant.50. 1.473

Hollande, L., Do Marcolino, I., Balaguer, P., Domenek, S., Gross, R. A., and Allais, F. (2019). Preparation of Renewable Epoxy-Amine Resins with Tunable Thermo-Mechanical Properties, Wettability and Degradation Abilities from Lignocellulose- and Plant Oils-Derived Components. Front. Chem. 7, 1-11. doi:10.3389/fchem.2019.00159

Horbury, M. D., Flourat, A. L., Greenough, S. E., Allais, F., and Stavros, V. G. (2018). Investigating Isomer Specific Photoprotection in a Model Plant Sunscreen. Chem. Commun. 54, 936-939. doi:10.1039/C7CC09061G

Horbury, M. D., Holt, E. L., Mouterde, L. M. M., Balaguer, P., Cebrián, J., Blasco, L., et al. (2019). Towards Symmetry Driven and Nature Inspired UV Filter Design. Nat. Commun. 10, 1-8. doi:10.1038/s41467-019-12719-z

Hussain, S., Rehman, A. U., Luckett, D. J., Blanchard, C. L., Obied, H. K., and Strappe, P. (2020). Phenolic Compounds with Antioxidant Properties from Canola Meal Extracts Inhibit Adipogenesis. Ijms 21, 1-17. doi:10.3390/ ijms 21010001

Huynh, N. T., Smagghe, G., Gonzales, G. B., Van Camp, J., and Raes, K. (2014). Enzyme-assisted Extraction Enhancing the Phenolic Release from Cauliflower (Brassica oleracea L. Var. Botrytis) Outer Leaves. J. Agric. Food Chem. 62, 7468-7476. doi:10.1021/jf502543c

Janvier, M., Hollande, L., Jaufurally, A. S., Pernes, M., Ménard, R., Grimaldi, M., et al. (2017). Syringaresinol: A Renewable and Safer Alternative to Bisphenol A for Epoxy-Amine Resins. ChemSusChem 10, 738-746. doi:10.1002/cssc. 201601595

Jaufurally, A. S., Teixeira, A. R. S., Hollande, L., Allais, F., and Ducrot, P.-H. (2016). Optimization of the Laccase-Catalyzed Synthesis of $( \pm)$-Syringaresinol and 
Study of its Thermal and Antiradical Activities. ChemistrySelect 1, 5165-5171. doi:10.1002/slct.201600543

Jokić, S., Cvjetko, M., Božić, D., Fabek, S., Toth, N., Vorkapić-Furač, J., et al. (2012). Optimisation of Microwave-Assisted Extraction of Phenolic Compounds from Broccoli and its Antioxidant Activity. Int. J. Food Sci. Technol. 47, 2613-2619. doi:10.1111/j.1365-2621.2012.03143.x

Jun, S.-Y., Sattler, S. A., Cortez, G. S., Vermerris, W., Sattler, S. E., and Kang, C. (2018). Biochemical and Structural Analysis of Substrate Specificity of a Phenylalanine Ammonia-Lyase. Plant Physiol. 176, 1452-1468. doi:10.1104/ pp.17.01608

Khoddami, A., Wilkes, M., and Roberts, T. (2013). Techniques for Analysis of Plant Phenolic Compounds. Molecules 18, 2328-2375. doi:10.3390/ molecules 18022328

Kikuzaki, H., Hisamoto, M., Hirose, K., Akiyama, K., and Taniguchi, H. (2002). Antioxidant Properties of Ferulic Acid and its Related Compounds. J. Agric. Food Chem. 50, 2161-2168. doi:10.1021/jf011348w

Knobloch, K.-H., and Hahlbrock, K. (1975). Isoenzymes of P-Coumarate: CoA Ligase from Cell Suspension Cultures of Glycine Max. Eur. J. Biochem. 52, 311-320. doi:10.1111/j.1432-1033.1975.tb03999.x

Koukol, J., and Conn, E. E. (1961). The Metabolism of Aromatic Compounds in Higher Plants. J. Biol. Chem. 236, 2692-2698. doi:10.1016/s0021-9258(19) 61721-.7Available at: http://www.ncbi.nlm.nih.gov/pubmed/14458851

Krause, M., Klit, A., Blomberg Jensen, M., Søeborg, T., Frederiksen, H., Schlumpf, M., et al. (2012). Sunscreens: Are They Beneficial for Health? an Overview of Endocrine Disrupting Properties of UV-Filters. Int. J. Androl. 35, 424-436. doi:10.1111/j.1365-2605.2012.01280.x

Kumar, N., and Pruthi, V. (2014). Potential Applications of Ferulic Acid from Natural Sources. Biotechnol. Rep. 4, 86-93. doi:10.1016/j.btre.2014.09.002

Laguna, O., Barakat, A., Alhamada, H., Durand, E., Baréa, B., Fine, F., et al. (2018). Production of Proteins and Phenolic Compounds Enriched Fractions from Rapeseed and Sunflower Meals by Dry Fractionation Processes. Ind. Crops Prod. 118, 160-172. doi:10.1016/j.indcrop.2018.03.045

Laguna, O., Odinot, E., Bisotto, A., Baréa, B., Villeneuve, P., Sigoillot, J.-C., et al. (2019). Release of Phenolic Acids from Sunflower and Rapeseed Meals Using Different Carboxylic Esters Hydrolases from Aspergillus niger. Ind. Crops Prod. 139, 111579. doi:10.1016/j.indcrop.2019.111579

Li, H., Wu, J., Rempel, C. B., and Thiyam, U. (2010). Effect of Operating Parameters on Oil and Phenolic Extraction Using Supercritical CO2. J. Am. Oil Chem. Soc. 87, 1081-1089. doi:10.1007/s11746-010-1594-x

Li, J., and Guo, Z. (2017). Complete Utilization of Rapeseed Meal to Produce Lipophilic Antioxidants, Protein, and Monosugars in a Concordant Manner. ACS Sustain. Chem. Eng. 5, 6218-6226. doi:10.1021/acssuschemeng.7b01171

Li, J., and Guo, Z. (2016). Concurrent Extraction and Transformation of Bioactive Phenolic Compounds from Rapeseed Meal Using Pressurized Solvent Extraction System. Ind. Crops Prod. 94, 152-159. doi:10.1016/j.indcrop.2016. 08.045

Li, Z., and Nair, S. K. (2015). Structural Basis for Specificity and Flexibility in a Plant 4-Coumarate:CoA Ligase. Structure 23, 2032-2042. doi:10.1016/j.str. 2015.08.012

Lin, L.-Z., and Harnly, J. M. (2010). Phenolic Component Profiles of Mustard Greens, Yu Choy, and 15 Other Brassica Vegetables. J. Agric. Food Chem. 58, 6850-6857. doi:10.1021/jf1004786

Lindermayr, C., Fliegmann, J., and Ebel, J. (2003). Deletion of a Single Amino Acid Residue from Different 4-coumarate:CoA Ligases from Soybean Results in the Generation of New Substrate Specificities. J. Biol. Chem. 278, 2781-2786. doi:10. 1074/jbc.M202632200

Lorenzen, M., Racicot, V., Strack, D., and Chapple, C. (1996). Sinapic Acid Ester Metabolism in Wild Type and a Sinapoylglucose-Accumulating Mutant of Arabidopsis. Plant Physiol. 112, 1625-1630. doi:10.1104/pp. 112.4 .1625

Lyon, G. D., and McGill, F. M. (1989). Inhibition of Polygalacturonase and Polygalacturonic Acid Lyase fromErwinia Carotovora subsp. Carotovora by Phenolics In Vitro. Potato Res. 32, 267-274. doi:10.1007/BF02357838

MacDonald, M. J., and D'Cunha, G. B. (2007). A Modern View of Phenylalanine Ammonia Lyase. Biochem. Cell Biol. 85, 273-282. doi:10.1139/O07-018

Maddox, C. E., Laur, L. M., and Tian, L. (2010). Antibacterial Activity of Phenolic Compounds against the Phytopathogen Xylella Fastidiosa. Curr. Microbiol. 60, 53-58. doi:10.1007/s00284-009-9501-0
Maeda, H., and Dudareva, N. (2012). The Shikimate Pathway and Aromatic Amino Acid Biosynthesis in Plants. Annu. Rev. Plant Biol. 63, 73-105. doi:10.1146/ annurev-arplant-042811-105439

Mathew, S., Abraham, T. E., and Zakaria, Z. A. (2015). Reactivity of Phenolic Compounds towards Free Radicals under In Vitro Conditions. J. Food Sci. Technol. 52, 5790-5798. doi:10.1007/s13197-014-1704-0

Matsuba, Y., Okuda, Y., Abe, Y., Kitamura, Y., Terasaka, K., Mizukami, H., et al. (2008). Enzymatic Preparation of 1-O-hydroxycinnamoyl-.BETA.-D-Glucoses and Their Application to the Study of 1-O-hydroxycinnamoyl-.BETA.-Dglucose-dependent Acyltransferase in Anthocyanin-Producing Cultured Cells of Daucus Carota and Glehnia Littoralis. Plant Biotechnol. 25, 369-375. doi:10.5511/plantbiotechnology.25.369

Matsuno, M., Compagnon, V., Schoch, G. A., Schmitt, M., Debayle, D., Bassard, J.-E., et al. (2009). Evolution of a Novel Phenolic Pathway for Pollen Development. Science 325, 1688-1692. doi:10.1126/science.1174095

Mohn, T., Cutting, B., Ernst, B., and Hamburger, M. (2007). Extraction and Analysis of Intact Glucosinolates-A Validated Pressurized Liquid Extraction/ liquid Chromatography-Mass Spectrometry Protocol for Isatis Tinctoria, and Qualitative Analysis of Other Cruciferous Plants. J. Chromatogr. A 1166, 142-151. doi:10.1016/j.chroma.2007.08.028

Moreno, D. A., V́lllora, G., Ruiz, J. M., and Romero, L. (2003). Growth Conditions, Elemental Accumulation and Induced Physiological Changes in Chinese Cabbage. Chemosphere 52, 1031-1040. doi:10.1016/S0045-6535(03)00330-8

Moreno-González, M., Girish, V., Keulen, D., Wijngaard, H., Lauteslager, X., Ferreira, G., et al. (2020). Recovery of Sinapic Acid from Canola/rapeseed Meal Extracts by Adsorption. Food Bioproducts Process. 120, 69-79. doi:10.1016/j. fbp.2019.12.002

Mouterde, L. M. M., and Allais, F. (2018). Microwave-Assisted KnoevenagelDoebner Reaction: An Efficient Method for Naturally Occurring Phenolic Acids Synthesis. Front. Chem. 6, 1-7. doi:10.3389/fchem.2018.00426

Mouterde, L. M. M., Peru, A. A. M., Mention, M. M., Brunissen, F., and Allais, F. (2020). Sustainable Straightforward Synthesis and Evaluation of the Antioxidant and Antimicrobial Activity of Sinapine and Analogues. J. Agric. Food Chem. 68, 6998-7004. doi:10.1021/acs.jafc.0c02183

Nair, R. B., Bastress, K. L., Ruegger, M. O., Denault, J. W., and Chapple, C. (2004). The Arabidopsis thaliana Reduced Epidermal Fluorescencel Gene Encodes an Aldehyde Dehydrogenase Involved in Ferulic Acid and Sinapic Acid Biosynthesis. Plant Cell 16, 544-554. doi:10.1105/tpc.017509

Nandasiri, R., Eskin, N. A. M., and Thiyam-Höllander, U. (2019). Antioxidative Polyphenols of Canola Meal Extracted by High Pressure: Impact of Temperature and Solvents. J. Food Sci. 84, 3117-3128. doi:10.1111/17503841.14799

Neelam, A. K, and Khatkar, K. K. (2020). Phenylpropanoids and its Derivatives: Biological Activities and its Role in Food, Pharmaceutical and Cosmetic Industries. Crit. Rev. Food Sci. Nutr. 60, 2655-2675. doi:10.1080/10408398. 2019.1653822

Nenadis, N., and Tsimidou, M. (2002). Observations on the Estimation of Scavenging Activity of Phenolic Compounds Using Rapid 1,1-Diphenyl-2Picrylhydrazyl (DPPH ) Tests. J. Amer Oil Chem. Soc. 79, 1191-1195. doi:10. 1007/s11746-002-0626-z

Nguyen, V. P. T., Stewart, J., Lopez, M., Ioannou, I., and Allais, F. (2020). Glucosinolates: Natural Occurrence, Biosynthesis, Accessibility, Isolation, Structures, and Biological Activities. Molecules 25, 4537. doi:10.3390/ molecules 25194537

Nicholson, R. L., and Hammerschmidt, R. (1992). Phenolic Compounds and Their Role in Disease Resistance. Annu. Rev. Phytopathol. 30, 369-389. doi:10.1146/ annurev.py.30.090192.002101

Nićiforović, N., and Abramovič, H. (2014). Sinapic Acid and its Derivatives: Natural Sources and Bioactivity. Compr. Rev. Food Sci. Food Saf. 13, 34-51. doi:10.1111/1541-4337.12041

Nowak, H., Kujawa, K., Zadernowski, R., Roczniak, B., and KozŁowska, H. (1992). Antioxidative and Bactericidal Properties of Phenolic Compounds in Rapeseeds. Fett Wiss. Technol. 94, 149-152. doi:10.1002/lipi.19920940406

Odinot, E., Fine, F., Sigoillot, J.-C., Navarro, D., Laguna, O., Bisotto, A., et al. (2017). A Two-Step Bioconversion Process for Canolol Production from Rapeseed Meal Combining an Aspergillus niger Feruloyl Esterase and the Fungus Neolentinus Lepideus. Microorganisms 5, 67. doi:10.3390/ microorganisms5040067 
Oueslati, S., Ksouri, R., Falleh, H., Pichette, A., Abdelly, C., and Legault, J. (2012). Phenolic Content, Antioxidant, Anti-inflammatory and Anticancer Activities of the Edible Halophyte Suaeda Fruticosa Forssk. Food Chem. 132, 943-947. doi:10.1016/j.foodchem.2011.11.072

Pei, K., Ou, J., Huang, J., and Ou, S. (2016). p-Coumaric Acid and its Conjugates: Dietary Sources, Pharmacokinetic Properties and Biological Activities. J. Sci. Food Agric. 96, 2952-2962. doi:10.1002/jsfa.7578

Peyrot, C., Mention, M. M., Brunissen, F., and Allais, F. (2020a). Sinapic Acid Esters: Octinoxate Substitutes Combining Suitable Uv Protection and Antioxidant Activity. Antioxidants 9, 782. doi:10.3390/antiox9090782

Peyrot, C., Mention, M. M., Fournier, R., Brunissen, F., Couvreur, J., Balaguer, P., et al. (2020b). Expeditious and Sustainable Two-step Synthesis of Sinapoyl-LMalate and Analogues: towards Non-endocrine Disruptive Bio-Based and Water-Soluble Bioactive Compounds. Green. Chem. 22, 6510-6518. doi:10. 1039/d0gc02763d

Peyrot, C., Peru, A. A. M., Mouterde, L. M. M., and Allais, F. (2019). ProlineMediated Knoevenagel-Doebner Condensation in Ethanol: A Sustainable Access to P-Hydroxycinnamic Acids. ACS Sustain. Chem. Eng. 7, 9422-9427. doi:10.1021/acssuschemeng.9b00624

Prapakornwiriya, N., and Diosady, L. L. (2014). Recovery of Sinapic Acid from the Waste Effluent of Mustard Protein Isolation by Ion Exchange Chromatography. J. Am. Oil Chem. Soc. 91, 357-362. doi:10.1007/s11746-013-2366-1

Raj Preeth, D., Shairam, M., Suganya, N., Hootan, R., Kartik, R., Pierre, K., et al. (2019). Green Synthesis of Copper Oxide Nanoparticles Using Sinapic Acid: an Underpinning Step towards Antiangiogenic Therapy for Breast Cancer. J. Biol. Inorg. Chem. 24, 633-645. doi:10.1007/s00775-019-01676-z

Reungoat, V., Gaudin, M., Flourat, A. L., Isidore, E., Mouterde, L. M. M., Allais, F., et al. (2020). Optimization of an Ethanol/water-Based Sinapine Extraction from Mustard Bran Using Response Surface Methodology. Food Bioproducts Process. 122, 322-331. doi:10.1016/j.fbp.2020.06.001

Schmid, J., and Amrhein, N. (1995). Molecular Organization of the Shikimate Pathway in Higher Plants. Phytochemistry 39, 737-749. doi:10.1016/00319422(94)00962-S

Sharma, A., Bányiová, K., Babica, P., El Yamani, N., Collins, A. R., and Čupr, P. (2017). Different DNA Damage Response of Cis and Trans Isomers of Commonly Used UV Filter after the Exposure on Adult Human Liver Stem Cells and Human Lymphoblastoid Cells. Sci. Total Environ. 593-594, 18-26. doi:10.1016/j.scitotenv.2017.03.043

Sharma, A., Thakur, S., Kumar, V., Kanwar, M. K., Kesavan, A. K., Thukral, A. K., et al. (2016). Pre-sowing Seed Treatment with 24-epibrassinolide Ameliorates Pesticide Stress in Brassica Juncea L. Through the Modulation of Stress Markers. Front. Plant Sci. 7, 1-12. doi:10.3389/fpls.2016.01569

Silambarasan, T., Manivannan, J., Krishna Priya, M., Suganya, N., Chatterjee, S., Raja, B., et al. (2014). Sinapic Acid Prevents Hypertension and Cardiovascular Remodeling in Pharmacological Model of Nitric Oxide Inhibited Rats. PLoS One 9, e115682. doi:10.1371/journal.pone.0115682

Sinichi, S., Siañez, A. V. L., and Diosady, L. L. (2019). Recovery of Phenolic Compounds from the By-Products of Yellow Mustard Protein Isolation. Food Res. Int. 115, 460-466. doi:10.1016/j.foodres.2018.10.047

Soubeyrand, E., Kelly, M., Keene, S. A., Bernert, A. C., Latimer, S., Johnson, T. S., et al. (2019). Arabidopsis 4-COUMAROYL-COA LIGASE 8 Contributes to the Biosynthesis of the Benzenoid Ring of Coenzyme Q in Peroxisomes. Biochem. J. 476, 3521-3532. doi:10.1042/BCJ20190688

Sova, M., and Saso, L. (2020). Natural Sources, Pharmacokinetics, Biological Activities and Health Benefits of Hydroxycinnamic Acids and Their Metabolites. Nutrients 12, 2190. doi:10.3390/nu12082190

Sparr Eskilsson, C., and Björklund, E. (2000). Analytical-scale Microwave-Assisted Extraction. J. Chromatogr. A 902, 227-250. doi:10.1016/S0021-9673(00) 00921-3

Szydlowska-Czerniak, A., and Tulodziecka, A. (2015). Application of Response Surface Methodology to Optimize Ultrasound-Assisted Extraction of Total Antioxidants from Brassica Napus Cultivars. Eur. J. Lipid Sci. Technol. 117, 491-502. doi:10.1002/ejlt.201400310

Taofiq, O., González-Paramás, A., Barreiro, M., Ferreira, I., and McPhee, D. J. (2017). Hydroxycinnamic Acids and Their Derivatives: Cosmeceutical Significance, Challenges and Future Perspectives, a Review. Molecules 22, 281. doi: $10.3390 /$ molecules 22020281
Thiel, A., Muffler, K., Tippkötter, N., Suck, K., Sohling, U., Hruschka, S. M., et al. (2015). A Novel Integrated Downstream Processing Approach to Recover Sinapic Acid, Phytic Acid and Proteins from Rapeseed Meal. J. Chem. Technol. Biotechnol. 90, 1999-2006. doi:10.1002/jctb.4664

Thiyam, U., Stöckmann, H., Zum Felde, T., and Schwarz, K. (2006). Antioxidative Effect of the Main Sinapic Acid Derivatives from Rapeseed and Mustard Oil ByProducts. Eur. J. Lipid Sci. Technol. 108, 239-248. doi:10.1002/ejlt.200500292

Toscano, S., Trivellini, A., Cocetta, G., Bulgari, R., Francini, A., Romano, D., et al. (2019). Effect of Preharvest Abiotic Stresses on the Accumulation of Bioactive Compounds in Horticultural Produce. Front. Plant Sci. 10, 1-17. doi:10.3389/ fpls.2019.01212

Vogt, T., Aebershold, R., and Ellis, B. (1993). Purification and Characterization of Sinapine Synthase from Seeds of Brassica Napus. Arch. Biochem. Biophys. 300, 622-628. doi:10.1006/abbi.1993.1086

Vogt, T. (2010). Phenylpropanoid Biosynthesis. Mol. Plant 3, 2-20. doi:10.1093/ $\mathrm{mp} / \mathrm{ssp} 106$

Wang, M., Zhu, X., Wang, K., Lu, C., Luo, M., Shan, T., et al. (2018). A Wheat Caffeic Acid 3-O-Methyltransferase TaCOMT-3D Positively Contributes to Both Resistance to Sharp Eyespot Disease and Stem Mechanical Strength. Sci. Rep. 8, 1-14. doi:10.1038/s41598-018-24884-0

Werck-Reichhart, D., and Feyereisen, R. (2000). Cytochromes P450 A Success Story. Genome Biol. 1, 1-9. doi:10.1186/gb-2000-1-6-reviews3003

$\mathrm{Xu}$, L., and Diosady, L. L. (2002). Removal of Phenolic Compounds in the Production of High-Quality Canola Protein Isolates. Food Res. Int. 35, 23-30. doi:10.1016/S0963-9969(00)00159-9

Yang, M., Zheng, C., Zhou, Q., Liu, C., Li, W., and Huang, F. (2014). Influence of Microwaves Treatment of Rapeseed on Phenolic Compounds and Canolol Content. J. Agric. Food Chem. 62, 1956-1963. doi:10.1021/jf4054287

Yoon, B. H., Jung, J. W., Lee, J.-J., Cho, Y.-W., Jang, C.-G., Jin, C., et al. (2007). Anxiolytic-like Effects of Sinapic Acid in Mice. Life Sci. 81, 234-240. doi:10. 1016/j.lfs.2007.05.007

Yu, G., Guo, T., and Huang, Q. (2020). Preparation of Rapeseed Oil with Superhigh Canolol Content and Superior Quality Characteristics by Steam Explosion Pretreatment Technology. Food Sci. Nutr. 8, 2271-2278. doi:10. $1002 /$ fsn 3.1502

Yu, X., Gouyo, T., Grimi, N., Bals, O., and Vorobiev, E. (2016). Ultrasound Enhanced Aqueous Extraction from Rapeseed Green Biomass for Polyphenol and Protein Valorization. Comptes Rendus Chim. 19, 766-777. doi:10.1016/j.crci.2016.03.007

Yun, K.-J., Koh, D.-J., Kim, S.-H., Park, S. J., Ryu, J. H., Kim, D.-G., et al. (2008). Anti-Inflammatory Effects of Sinapic Acid through the Suppression of Inducible Nitric Oxide Synthase, Cyclooxygase-2, and Proinflammatory Cytokines Expressions via Nuclear Factor- $\mathrm{\kappa B}$ Inactivation. J. Agric. Food Chem. 56, 10265-10272. doi:10.1021/jf802095g

Zago, E., Lecomte, J., Barouh, N., Aouf, C., Carré, P., Fine, F., et al. (2015). Influence of Rapeseed Meal Treatments on its Total Phenolic Content and Composition in Sinapine, Sinapic Acid and Canolol. Ind. Crops Prod. 76, 1061-1070. doi:10. 1016/j.indcrop.2015.08.022

Zhang, Z., He, S., Liu, H., Sun, X., Ye, Y., Cao, X., et al. (2020). Effect of pH Regulation on the Components and Functional Properties of Proteins Isolated from Cold-Pressed Rapeseed Meal through Alkaline Extraction and Acid Precipitation. Food Chem. 327, 126998. doi:10.1016/j.foodchem. 2020.126998

Zhu, Y., and Ralph, J. (2011). Stereoselective Synthesis of 1-O- $\beta$-Feruloyl and 1-O$\beta$-Sinapoyl Glucopyranoses. Tetrahedron Lett. 52, 3729-3731. doi:10.1016/j. tetlet.2011.05.038

Conflict of Interest: The authors declare that the research was conducted in the absence of any commercial or financial relationships that could be construed as a potential conflict of interest.

Copyright (c) 2021 Nguyen, Stewart, Ioannou and Allais. This is an open-access article distributed under the terms of the Creative Commons Attribution License (CC $B Y)$. The use, distribution or reproduction in other forums is permitted, provided the original author(s) and the copyright owner(s) are credited and that the original publication in this journal is cited, in accordance with accepted academic practice. No use, distribution or reproduction is permitted which does not comply with these terms. 